\title{
A RECIPE FOR CELEBRITY: \\ POLICY \\ AND \\ AN ENGLISH CANADIAN STAR SYSTEM
}

By

Catharine 'Thorsteinson, B.A.

A thesis submitted to the Faculty of

Graduate Studies and Research in partial fulfilment

of the requirements for the degree of

Master of Arts

in Canadian Studies

\author{
Carleton University \\ OTTAWA, Ontario \\ January, 2005
}

Copyright@ Catharine Thorsteinson, 2005 


$\begin{array}{ll}\begin{array}{l}\text { Library and } \\ \text { Archives Canada }\end{array} & \begin{array}{l}\text { Bibliothèque et } \\ \text { Archives Canada }\end{array} \\ \begin{array}{l}\text { Published Heritage } \\ \text { Branch }\end{array} & \begin{array}{l}\text { Direction du } \\ \text { Patrimoine de l'édition }\end{array} \\ \begin{array}{l}\text { 395 Wellington Street } \\ \text { Ottawa ON K1A ON4 }\end{array} & \begin{array}{l}\text { 395, rue Wellington } \\ \text { Ottawa ON K1A ON4 } \\ \text { Canada }\end{array}\end{array}$

Your file Votre référence

ISBN: 0-494-00730-3

Ourfile Notre référence

ISBN: 0-494-00730-3

NOTICE:

The author has granted a nonexclusive license allowing Library and Archives Canada to reproduce, publish, archive, preserve, conserve, communicate to the public by telecommunication or on the Internet, loan, distribute and sell theses worldwide, for commercial or noncommercial purposes, in microform, paper, electronic and/or any other formats.

The author retains copyright ownership and moral rights in this thesis. Neither the thesis nor substantial extracts from it may be printed or otherwise reproduced without the author's permission.
AVIS:

L'auteur a accordé une licence non exclusive permettant à la Bibliothèque et Archives Canada de reproduire, publier, archiver, sauvegarder, conserver, transmettre au public par télécommunication ou par l'Internet, prêter, distribuer et vendre des thèses partout dans le monde, à des fins commerciales ou autres, sur support microforme, papier, électronique et/ou autres formats.

L'auteur conserve la propriété du droit d'auteur et des droits moraux qui protège cette thèse. $\mathrm{Ni}$ la thèse ni des extraits substantiels de celle-ci ne doivent être imprimés ou autrement reproduits sans son autorisation.
In compliance with the Canadian

Privacy Act some supporting forms may have been removed from this thesis.

While these forms may be included in the document page count, their removal does not represent any loss of content from the thesis.
Conformément à la loi canadienne sur la protection de la vie privée, quelques formulaires secondaires ont été enlevés de cette thèse.

Bien que ces formulaires aient inclus dans la pagination, il n'y aura aucun contenu manquant.

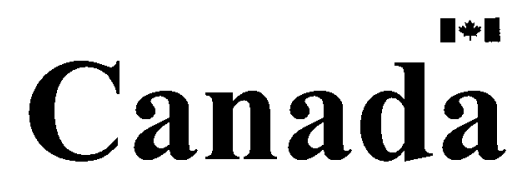




\begin{abstract}
Recent discussions (1998-2003) in Canadian broadcasting policy have focused attention on the crisis in Canadian drama and the need for an English-Canadian star system. These discussions drew attention to the fact that very little is known about the current environment of English-Canadian star system. The author addresses this gap in policy and academic knowledge by conducting a study into the extent and nature of English-Canadian celebrity coverage in print media. Through an examination of seven Canadian celebrities in four print media sources, the author presents three main conclusions: the print media surveyed displayed a regional bias in their coverage of celebrities; there is an insufficient amount of celebrity coverage; and the desired type of celebrity making articles are too few in number to cultivate celebrity. As a result of these findings, the author concludes that English-Canadian print media are currently limited in their ability to sustain the visibility complex necessary for stardom.
\end{abstract}




\section{ACKNOWLEDGEMENTS}

This thesis, A recipe for celebrity: Policy and An English Canadian Star System would not have become a reality without the help and support of many people - most importantly my supervisor Paul Litt, to whom I express my sincere gratitude. Thank you for all your hard work.

I would also like to acknowledge my family, friends and colleagues for their on-going support throughout the past year and a half. Specifically, I would like to thank my sister Janice for keeping me on-track throughout the month of July 2004. Her daily checklists of what I had to accomplish, although a bit annoying, were somewhat humorous and were the reason the first draft was completed. Thanks for the encouragement and 'tough-love.' I apologize that you saw more of my thesis than the City of Ottawa during the month you were here.

Nicole Edwards was an incredible roommate and friend during this time. She never complained about the piles of papers I had stacked around the house or the sticky notes that were all over the place. Thank you for your patience and constantly listening while I was working through ideas.

Special thanks must be extended to Sandra Lopes. The countless hours of editorial support by Sandra went far beyond what any friend could ask. Your belief in this thesis and me was an encouragement to carry on. Thank you so much for everything, you might know this topic better than I now.

Also a sincere thanks goes out to my friends Karine Plouffe, Julie Mecke, Angela Archibald and Marguerite Sullivan-Lee who were always willing to listen whenever I needed an outlet, thank you all very much.

Finally a very special thanks goes out to my parents, Pat and Wayne, my grandfather, Tom and to my sister Christy, your constant love and support is unbelievable. 


\section{TABLE OF CONTENTS}

List of Tables $\quad v i$

List of Appendices vii

INTRODUCTION

\section{PART I}

CHAPTER 1:

Policy Connections: Canadian Television Drama, Audiences, \& an English Canadian Star System

CHAPTER 2:

$31-45$

Key Elements of Sustainable Celebrity

\section{PART II}

CHAPTER 3:

Canadian Celebrity in English-Canadian Print Media

CHAPTER 4:

76-89

The State of English-Canadian Celebrity

Culture: Analysis \& Recommendations

CONCLUSION

Appendix

95-112

Bibliography

113-120 


\section{LIST OF TABLES}

\section{TABLES}

Table 3.1 Summary of print media articles 51

Table 3.2 Summary of print media articles - Rick Mercer 59

Table 3.3 Summary of print media articles - Sarah Polley 61

Table 3.4 Summary of print media articles - Paul Gross 63

Table 3.5 Summary of print media articles - Cathy Jones 64

Table 3.6 Summary of print media articles - Mary Walsh 66

Table 3.7 Summary of print media articles -

Table $3.8 \quad$ Summary of print media articles - Sonja Smits $\quad 68$

$\begin{array}{lll}\text { Table } 3.9 & \text { Total Number of Articles by Celebrity } & 70\end{array}$

$\begin{array}{lll}\text { Table 3.10 Breakdown of Headlines by Celebrity } & 70\end{array}$

Table 3.11 Breakdown of Lead Lines by Celebrity 71

$\begin{array}{lll}\text { Table 3.12 } & \text { Breakdown of Illustrations by Celebrity } & 72\end{array}$

Table 3.13 Breakdown of Content by Celebrity 73

$\begin{array}{lll}\text { Table 3.14 Breakdown of Name Dropping by Celebrity } & 74\end{array}$

Table 4.1 Breakdown of Articles by Celebrity and Source $\quad 77$

Table 4.2 Accessibility of Celebrities $\quad 80$

Table 4.3 'Illusion of Intimacy' in Print Media $\quad 83$

$\begin{array}{ll}\text { Table 4.4 Celebrity Profiling versus Name Dropping: } & \\ & \text { Cathy Jones }\end{array}$

Table 4.5 Industry versus General Interest Stories: Mary Walsh $\quad 84$

Table 4.6 The News-worthy Celebrity in Print Media 85

Table 4.7 Awards, Events and Politics: Rick Mercer 86 


\section{LIST OF APPENDICES}

Appendix 1

Canada - Top Ten Programmes 1998

95

Appendix 2

Canada - Top Ten Programmes 2001

96

Appendix 3

Summary Domestic Programmes as a

Percentage of Top Ten Programmes Viewed

in 1998 and 2001

97

Appendix 4

Summary of Drama and Comedy Program

Hours Broadcast During Peak Viewing Hours

Appendix 5

(7:00 PM - 11:00 PM)

98

Filmography - Rick Mercer

99

Appendix 6

Filmography - Sarah Polley

100

Appendix 7

Filmography - Paul Gross

102

Appendix 8

Filmography - Cathy Jones

105

Appendix 9

Filmography - Mary Walsh

106

Appendix 10

Filmography - Sonja Smits

108

Appendix 11

Filmography - Nicholas Campbell

109 


\section{INTRODUCTION}

Do we, Canadians have a unique culture? Is it worth defending? If so, how best to do so? These questions have preoccupied Canadians for decades. As our cultural industries struggle to stay afloat in a Canada dominated by American culture, these questions have increasing significance, particularly for the Canadian broadcasting system.

The Canadian broadcasting system is in a constant struggle to balance economic success with the promotion of Canadian identity. This struggle is a result of the ongoing involvement of the federal government in the system. Canadian broadcasting has always been under the control of the federal government to some extent. From 1932 on, it has been regarded as a public broadcasting system, and, as such, has been governed by successive pieces of Canadian legislation with public policy objectives. From the earliest broadcasting policy to the most recent we see a struggle for a system that is both economically viable and will deliver public goods such as Canadian identity, unity and citizenship.

\section{Purpose of the Study}

Recent discussions (1998-2003) in Canadian broadcasting policy have focused attention on the crisis of Canadian drama and the need for an English-Canadian star system. This discussion has evolved from the Canadian Radio-Television and Telecommunications Commission's (CRTC) 1999 Television Policy, and two subsequent reports: Dramatic Choices (2003), commissioned by the CRTC, and Our Cultural Sovereignty: The Second Century of Canadian Broadcasting (2003), by the Standing 
Commission on Canadian Heritage. These policies and reports discuss the current state of Canadian television broadcasting. They agree that Canadian drama is in a crisis and that its survival (and by extension that of the Canadian broadcasting system as a whole) relies on developing an English-Canadian star system.

Those reports drew attention to the fact that very little is known about the current environment of English-Canadian celebrity culture. The CRTC has already made regulatory decisions aimed at fostering an English-Canadian star system and is currently studying other options to help promote Canadian drama. Yet these decisions and discussions are developing without a full understanding of the nature and extent of celebrity in Canada. Before we can continue with these discussions it is imperative that these gaps in the knowledge of Canadian celebrity be addressed. ${ }^{1}$ This study will address this gap in knowledge. Its purpose is to begin to explore what English-Canada needs to do to cultivate a celebrity culture.

To provide context for this analysis, this study first traces the evolution of English Canadian celebrity discourse. It then surveys secondary research on celebrity culture, identifying the key elements necessary for celebrity culture. Together the first two chapters of this study identify the problem and develop a model of celebrity culture against which the case of English Canada can be compared.

Since there is little literature available on English Canadian celebrity culture, information on it had to be gathered through primary research. A similar study into the

\footnotetext{
${ }^{1}$ As the Symons Report concluded in 1972: "the most valid and compelling argument for Canadian Studies is the importance of self-knowledge, the need to know and to understand ourselves: who we are; where we are in time and space; where we have been; where we are going; what we possess; what our responsibilities are to ourselves and to others" (Symons, 1975: 12). This study is propelled by the belief that it is crucial to have self-knowledge and to understand our environment before we can create solutions.
} 
production of celebrity has been conducted in Australia. In Fame Games (2000), Turner, Bonner and Marshall analyzed Australian media to determine the nature of celebritymaking. They conducted a content analysis of selected programs and publications in television, newspapers and magazines (16). From the results of their study, they were able to "fill the gap in media research" (23) in Australia. As they note, before their contribution there was almost no research into the Australian celebrity production industry (23). ${ }^{2}$ In addition to making a substantial contribution to our understanding of the cultural function of celebrity and the production of celebrity, their analysis informs academic debates on media practice internationally.

The methodology employed in the Australian study is to date the most comprehensive approach to exploring celebrity, but it is too complex for this study to emulate in its entirety. Its subject matter included, but was not limited to, the publicity industry, television entertainment news magazine programs and news-casts, women's magazines, tabloids and celebrity interviews. In order to fully comprehend the extent and nature of celebrity, it would be necessary to explore these and other components of celebrity making. However, that task is beyond the scope of this thesis.

As a result it was necessary to choose a source of data that would be manageable yet significant. In Self-Exposure (2002) Ponce de Leon begins his discussion on celebrity-making by reminiscing over the events that led his framing of the study: "I am convinced that the news media - defined broadly to include publications and programs that many professional journalists revile - are the most important institutions that sustain the culture of celebrity" (5). He continues by noting, "by virtue of their ability to make

\footnotetext{
${ }^{2}$ Unfortunately similar surveys of American media are not available. And although such research would provide a useful comparison to the study, it is beyond the parameters of this study to conduct such research.
} 
public figures visible and familiar to millions of people who have never encountered them in the flesh, it is the news media that literally create celebrities" (5). Taking a cue from Ponce de Leon, this study focuses on news media.

Since even this narrower focus would involve multiple media and would require a complex cross-media comparative methodology, it was decided to focus on just one medium. Print media was the obvious choice as it was a readily available for research purposes. The necessity of settling on a manageable set of data of course limits the comprehensiveness and conclusiveness of this study. The limited sample of print media investigated in this study nevertheless provide some interesting insights and suggestions for future policy research on the possibility of creating an English-Canadian star system. Celebrity making is a process. To understand this process, this study traced particular subjects through the coverage (amount and type) they received in print media over a set period of time. Through a survey of print media, the author assesses how print media complements television by providing the cross-media exposure critical to celebrity-making. The results of this primary research reveal certain traits in Canadian celebrity culture which, upon comparison with other celebrity systems, reveal weaknesses in the Canadian system.

\section{Chapter Outline}

This study has been broken into two parts. The first part (Chapters One and Two) provides contextual information that helps to situate the case study of English Canada. The first chapter introduces the interrelated topics of television, drama, audience, celebrity and Canadian broadcasting policy and how they have made an English- 
Canadian star system a pressing policy issue. One purpose of this chapter is to establish the connections between television, drama, audience and celebrity, something that current policy discussion has not yet done. Once these links are made, this chapter will trace the origins and development of discussions about the 'Crisis in Canadian Drama' and the resulting broadening of Canadian broadcasting policy discourse beyond the themes of economics and Canadian content to a concern with creating and sustaining Canadian audiences.

The second chapter begins the discussion on celebrity. Since this study is exploring 'how to cultivate an English-Canadian star system,' it was necessary to outline what scholars have suggested about the production of celebrity. This chapter suggests the visibility complex (reach, accessibility, 'illusion of intimacy' and news-worthiness) is the key element necessary for creating and maintaining celebrity. This discussion suggests that when one element of the visibility complex is absent, celebrity is impossible to achieve or sustain. Citing examples from different periods and discussing the emergence of the various tools of the visibility complex, a working model of celebrity building is created.

The second part (Chapters Three and Four) is a case study of English-Canadian print media. This section is concerned with the degree to which Canadian print media complement television to provide the cross-media promotion critical to celebrity-making and whether they currently provide the kind of coverage that best cultivates celebrity.

Chapter Three is a presentation and summary of primary research on seven Canadian celebrities who were traced through four print media from 1998 to 2003. This chapter provides a brief biographical sketch of these Canadian celebrities and the 
research findings for each. The type of coverage is tracked within the following categories: headlines, illustrations, leadlines, name dropping, and content (industry, awards, celebrity profiles, events, politics and general interest).

Chapter Four analyzes the implications of the data presented in Chapter Three for the cultivation of a Canadian celebrity culture. It analyzes this data in terms of the visibility complex (reach, ease of access, 'illusion of intimacy' and news-worthiness) presented in Chapter Two. This analysis reveals some of the shortcomings of Canadian print media as tools of celebrity production. There are three main conclusions:

- The print media surveyed displayed a regional bias in their coverage of celebrities;

- There is an insufficient amount of celebrity coverage, i.e. Canadian celebrities in general do not get the print media coverage necessary to sustain visibility; and

- The most highly desired type of celebrity making articles (profiles) are too few in number to cultivate celebrity.

The conclusion is that Canadian print media are currently limited in their ability to sustain the visibility complex necessary for stardom. This conclusion, though tentative (given the limited scope of this study), nevertheless suggests directions for future policy research and policy making. These implications are explored in the conclusion of this study. 
PART I

Reproduced with permission of the copyright owner. Further reproduction prohibited without permission. 


\section{CHAPTER 1: POLICY CONNECTIONS:}

\section{CANADIAN TELEVISION DRAMA, AUDIENCES AND AN ENGLISH-CANADIAN STAR SYSTEM}

The Canadian broadcasting system is a public system and as such, the Canadian government plays a significant role in creating and implementing policy to ensure its maintenance. The government fulfills its duties through the Department of Canadian Heritage, which in turn implements policy through an agency, the Canadian RadioTelevision Telecommunications Commission (CRTC) and two crown corporations, the Canadian Broadcasting Corporation (CBC) and Telefilm Canada. The Ministry relies on its Broadcasting Policy and Innovation Branch to advise the Minister on broadcasting policy matters. The Branch "formulate(s) policies, proposes legislation and designs and administers programs in relation to the Canadian broadcasting system" $(\mathrm{PCH}, 2004)$.

It is also through the Department of Canadian Heritage that the government fulfills its financial obligations to the Canadian broadcasting system. The Department of Canadian Heritage funds Canadian television programs and feature films through the Canadian Television Fund (CTF). The CTF is an autonomous agency that is responsible for eligibility criteria and individual funding decisions. The Department is also responsible for parliamentary appropriations for the $\mathrm{CBC}$ and Telefilm Canada.

The government's regulatory obligations in the broadcasting system are fulfilled through the CRTC. The CRTC is an independent authority that, among other responsibilities, issues licences and creates policy under the directives of the Broadcasting Act. The CRTC is charged with the task of balancing the needs of broadcasters with the regulations set forth by the Broadcasting Act. 
Over the past five years, we have witnessed the beginning of a shift in the government's approach to maintaining the Canadian television broadcasting system. The government has begun to recognize that the audience - the Canadian people - plays a crucial role in the health and viability of the Canadian broadcasting system. Previously, policy had only focused on production through funding and Cancon regulations without much concern for reception. As a result, broadcasting policy and other supporting policies have increasingly incorporated the interests and responses of Canadians as participants in the broadcasting process. The purpose of this chapter is two-fold. First, it will briefly discuss the inter-related topics of television, drama, audience and celebrity in order to situate subsequent discussion on Canadian broadcasting policy. That discussion then proceeds with an exploration of the shift in broadcasting policy and the result of this shift, specifically, a new interest in developing an English-Canadian star system.

\section{Putting the Canadian back into the Canadian Broadcasting System:}

\section{Conceiving of a star system}

As more specialty channels are licensed there has been an increase in the availability of Canadian programming. However, this is accompanied by a dramatic shift in the type of programming being offered. Whereas dramatic programming once dominated television, reality programming now dominates. From home repairs to dating and consumer advice, reality programming remains the preferred programming of most Canadian broadcasters. ${ }^{1}$

\footnotetext{
${ }^{1}$ In a study conducted by Nordicity Group Limited (NGL), "Viewership to Domestic Programming and Regulatory / Incentive Frameworks in OECD Countries and Canada," (2003) it was concluded that "scripted drama and sitcom programming - whether domestic or foreign in source has lost audiences in favour of 'reality' programming genre" (11).
} 
As a result, dramatic programming, foreign or Canadian, has a difficult time finding a place within this new television landscape.

Television has not only become our primary channel for information and entertainment, it is also the principal source of the imaginative forms through which we perceive ourselves and the world (Alder, 1981: xiv). Television stimulates imagination in two ways: it is both a window to the outside world and a mirror that lets us see ourselves.

Television can also act as a mediator. It is a tool we use to filter the endless amounts of information that we receive daily. Television is a mediator between our individual lives and the larger life of the nation and the world; between fantasy and fact; between old values and new ideas; between our desire to seek escape and our need to confront reality (Alder, 1981: xii). Therefore, television is a realm of negotiation. It is a medium through which we can confront the contradictions of reality (even if some of these contradictions are caused by television), and construct from them our own meaning.

According to Ellis, "television attempts to define, tries out explanations, creates narratives, talks over, makes intelligible, tries to marginalize, harnesses speculation, tries to make fit and, very occasionally, anathematizes" (55). He suggests that although television tries to frame the information we receive, it ultimately comes to no conclusion; it merely attempts to 'work-through'. Of the various types of television programming, drama is the most effective genre at working-through the issues facing society (57).

Television drama cannot do this work if it does not reach an audience (Marshall, 1997: 21). The lack of a Canadian audience for Canadian content has long been noted by 
many academics. The phenomenon is referred to as the 'absent audience.'2 The lack of Canadian audiences for Canadian entertainment programming has been linked to "economics and taste" (Acland, 2001: 276). The economic side of the problem is simply the American dominance in the entertainment industry. As for taste, Canadians tend to view Canadian content as "elitist or nationalistic". This has resulted in what Acland (2001) refers to as the 'expo-mentality', in which viewing is more commonly associated with fringe events like festivals (280). It has been pushed aside; creating a mentality that it is secondary to mainstream (American) programming. Therefore, Canadian content has been unable to establish its own mainstream audience. Academics have long argued that to create an audience, there needs to be a significant effort made to alter this mentality (Acland, Harcourt, Dorland). The focus must be placed on building and maintaining a Canadian audience for Canadian content. Celebrity is recognized as one of the most effective tools for creating and maintaining audiences, particularly in the drama genre. Yet, maintaining and developing audiences for Canadian programming has never been a real priority of Canadian broadcasters and Canadian broadcasting policy. ${ }^{4}$

Why is celebrity connected to the success of homegrown English-Canadian drama? The celebrity system invites the audience into the personal lives of the actors, creating a sense of intimacy: it provides a delusion of a direct personal relationship in an impersonal, mass mediated market place (Marshall, 1997: 128). The television celebrity provides familiarity to the audience. As the audience becomes more familiar with the celebrity, a loyalty is created, influencing the audience to seek out the celebrity whenever

\footnotetext{
2 Peter Harcourt coins the term absent audience in "The Invisible Cinema" (1978) in Cine Tracts (1) 4, 4849.

${ }^{3}$ Although Acland is discussing Canadian film, he arguments of Canadians mentality towards Canadian programming apply equally well to Canadian television programming.

${ }^{4}$ This statement will be more closely examined in the following section (p. 15).
} 
possible. Once this relationship is created, the star system begins to operate. The audience will almost always seek out the celebrity, regardless of the quality of the production/performance (Woodward, 2003: 61).

Celebrity is dependent on there being a relationship between performers and their audiences extraneous to the performance. The audience needs to feel connected to celebrity; this is what creates a demand for the celebrity. Television drama makes audiences feel that they know the performers personally (Marshall, 1997: 119). In part this is because drama personalizes ideas and concepts whenever it can, most often through the individual (Langer, Television Personalities). But the familiarity that a drama develops must be supported through other cultural products which provide external validation. They extend familiarity, validate it, and sustain it between dramatic productions.

\section{Celebrities, Audiences and an English-Canadian Star System}

Before proceeding further it is necessary to explore "celebrity." What is a celebrity? In its most simplistic definition, a celebrity is a person that the public is interested in (Turner, Bonner and Marshall, 2000: 9). However, by this definition, anyone whom the public is interested in, at any given time, could be considered a celebrity. True celebrity is much more complex than this simple definition. The term celebrity has a long history in which its transformation has been quite significant.

Marshall outlines four phases of the term celebrity. Historically, it was deeply rooted in religious celebration (Marshall, 1997: 5). In the eighteenth and nineteenth centuries the term began a transformation into its modern definitions, becoming the 
"condition of being much extolled or talked about; famousness, notoriety" (Marshall, 1997: 5). Today, a celebrity is understood to be a public personality, "a celebrated person, a public character" (Marshall, 1997: 5).

The above definition of contemporary celebrity is broad and does not elaborate on the more complex aspects of celebrity that exist, including its many different types. Monaco (1978) suggests that there are four categories of celebrity; heroes, stars, quasars, and paracelebrities (10). The categorization depends upon how celebrity is obtained. Heroes obtain celebrity for "what they do" (Monaco, 1978: 11). An example of this type of celebrity would be Terry Fox, who is celebrated for his achievement. On the other hand, a star reaches celebrity for "what they are" (Monaco, 1978: 10). However, Monaco (1978) makes the distinction that this category does not only refer to actors; politicians can also be stars (11). The reasoning is that stars "play themselves" (Monaco, 1978: 11). Thus actors, politicians and even athletes can be considered 'stars.'

The more complicated type of celebrity that Monaco describes is the quasar. Quasars gain their celebrity for "what we think they do" (Monaco, 1978: 10). The previous two types of celebrity are thought to have control over their images; however a quasar has very little control over his or her image. Monaco suggests that they are victims of celebrity since "it is not what they are or what they do, but what we think they do that fascinates us" (Monaco, 1978: 11). An example of this type of celebrity would be Monica Lewinsky, who in the early stages of her celebrity had no control over her celebrity image.

The final type of celebrity that Monaco describes is the 'paracelebrity'. The paracelebrity, unlike the previous types described, is not known for what they are or do, 
or even what we think they might be. The paracelebrity gains their recognition for whom they know. "They are well-known for being known by people who are well-known for their well-known-ness" (Monaco, 1978: 4). This is a rather complicated definition, and perhaps an example of a paracelebrity would help to simplify it. Walter Gretzky would be considered a type of celebrity within Canada. However, his form of celebrity is that of the paracelebrity. Walter Gretzky is not known for anything that he has done, rather he is known for his relationship to celebrity Wayne Gretzky. Thus he is 'known for knowing' a celebrity.

It has been generally acknowledged that the star system is one of the most effective means of developing audience loyalty. In a comprehensive analysis of CBC dramatic television programming from 1952 - 1986, Mary Jane Miller (1987) is quick to note that the CBC did not promote the lead actors in its shows, choosing rather to promote the name of the show alongside the CBC logo (12). Miller suggests that this decision contributed to the failure of many dramatic programs (12). However, it was not only the public broadcaster that neglected the Canadian star.

Private broadcasters did not do much better in making the promotion of Canadian actors a priority. As far as private broadcasters are concerned, the bottom line is profit. Jeffery (1996) suggested "English-language private broadcasters became rich by selling audiences for imported U.S. shows to advertisers, not by producing or purchasing shows of comparable quality in Canada, nor by promoting homegrown stars" (207). What becomes painfully obvious is that from the very beginnings of Canadian television, broadcasters neglected the audience for Canadian programming. 
However, over the past five years, the federal government and broadcasters have begun to shift their focus and reconsider the importance that audiences play in maintaining a broadcasting system. A new emphasis on developing and sustaining a Canadian audience is a central theme in policies and funding agencies. The reason for the shift in the government mentality is mainly due to the current crisis that Canadian drama is facing. The conclusion is that Canadian drama needs an English-Canadian star system.

Throughout the decades the interests of private broadcasters have been represented by the Canadian Association of Broadcasters (CAB). The interests of private broadcasters have always been distinct from that of the public system of broadcasting. For private broadcasters, broadcasting is a business.

The economic product...is the audiences [private broadcasters] supply to advertisers. The product is not...the program offered. The economic characteristics of the industry, therefore, inevitably come into conflict with the broader social and political objectives of the broadcasting regulation (McFadyen, Hoskins and Gillen, 1980: I).

It is important to recognize the profit driven interest of private broadcasters, yet there can be common ground between the public system and private interests.

\section{Pervasive Themes in Broadcasting Policy: Economic Viability and Canadian Content}

The central focus of Canadian television broadcasting policy has been to sustain a healthy and viable Canadian broadcasting system. Since its beginnings, the Canadian television broadcasting system has had to protect itself from American influences. Our 
proximity to the United States cannot be ignored when discussing Canadian broadcasting policy. Not only was the CBC charged with the process of launching the new medium of television in the late $1940 \mathrm{~s}$, it also had to establish a system independent of the American system. Thus, in pursuit of a broadcasting system that is 'healthy and viable' and distinct from that of the United States, the government has introduced numerous regulations, funding mechanisms and broadcaster incentives. As Peers suggested, the late 1940s was a critical time for public policy makers, as they needed to weigh the priorities of private ownership (economic and market driven) versus broadcasting as public service (national objectives) (1979: $x v i)$. Thus the strategy behind the ensuing policies is clear; the government believes that there is a need for economic viability and access to Canadian content. In fact, these two themes have dominated the discussions in broadcasting policy, producing an endless array of documents, books and articles.

The economic viability of the Canadian Broadcasting System has been a central focus of most broadcasting policies implemented. Economic concerns were a central focus of the Massey Commission's discussion of the developing broadcasting system. The Massey Report (1951) concluded that the medium of television was far more costly than that of radio and as a result a significant amount of research and planning was needed because the system could not afford "costly experiments" (302). However, for the Massey Commission economic concerns were second to content considerations of the new medium.

In the Massey Report (1951) the discussion on television broadcasting was dominated by concerns about access to Canadian content. Canadian content on Canadian television remains a key priority for the Government. As noted in the Massey Report 
(1951) "like radio it [television] is a valuable instrument of national unity..." (301). It was subsequently recommended by the Massey Report that no private broadcasters be licensed until the $\mathrm{CBC}$ had developed a substantial quantity of 'national' programs. Once this was achieved, private broadcasters would serve as outlets for these programs (303). According to Raboy (1990), the central position of the government was to maintain the national system (107).

The focus of economics and Canadian content were further addressed in 1952 by J.J. McCann, Minister of National Revenue:

The government believes, with the royal commission, that television should be developed in Canada with the aim of benefiting our national life and that it should have the structure and means required by Canadian conditions to ensure an adequate amount of suitable Canadian programs... [in this system] There will be plenty of opportunity for enterprise by private interests in television broadcasting... (McCann, 1952: 409-410 in Bird, 1988: 240-241).

Again there was a preoccupation within the government that this mixed public and private television broadcasting system needed to satisfy both economic and content concerns.

This first decade of Canadian television was accompanied by a spate of broadcasting policy. Within six years of the Massey Commission, the Report of the Royal Commission on Broadcasting (1957) was released. Conflicts between economic and Canadian content concerns had peaked at this time and the Fowler Commission was charged with task of resolving these conflicts (Bird, 1988: 250). 
The Fowler Commission also laid the groundwork for the infamous Canadian Content Regulations in 1959. The Fowler Commission recommended replacing the CBC as the regulatory body of broadcasting with a new independent authority (Peers, 1979: 101). Under the authority of the Broadcasting Act (1958), the Board of Broadcast Governors $(\mathrm{BBG})$ was established. One of the first initiatives of the $\mathrm{BBG}$ was the implementation of Canadian Content Regulations. These regulations required all Canadian broadcasters to broadcast a minimum number of Canadian programs (BBG, 1959: Section 6 in Bird, 1988: 288). Although the specifics of these regulations have altered over the decades, the intent remains the same: reserving a space for Canadian programs.

During the BBG's tenure as the regulating authority the tensions between economic and Canadian content priorities were continually addressed. A succession of policies were implemented and amended in an attempt to balance the economic needs of broadcasters with the nation building objectives of government. For instance, in 1962 the BBG introduced commercial rewards for broadcasters who fulfilled their Canadian content quotas (Bird, 1988: 294).

This early era of television broadcasting policy in Canada was crucial in establishing key policy themes and priorities that continue to pervade broadcasting policy. In 1968, under the directive of the Broadcasting Act, the name of the regulatory authority was changed to the Canadian Radio Commission (and later to the Canadian Radio-Television Telecommunications Commission [CRTC]). The CRTC has continued implementing policies that satisfy both the economic needs of broadcasters and content requirements of the public system. 
The importance of economic viability is still a dominant theme in twenty-first century broadcasting policy. Market economies are a determining factor in CRTC decisions to granting new broadcasting licenses. The CRTC determines whether or not a particular market can "economically" support another broadcaster; rather than allowing a free-market, it limits the number of broadcasters based on economic feasibility. Furthermore, the CRTC ensures economic support of the broadcasting system by setting conditions of license requiring the broadcaster to expend a certain amount within the Canadian broadcasting system.

At a micro-level, these policies have helped to create and sustain an economically viable Canadian broadcasting system. In other words, these policies have fulfilled their purpose. For instance, according to the CRTC's 2003 Broadcasting Monitoring Report, the Canadian broadcasting system was extremely profitable. In 2002, revenues for most Canadian broadcasters had significantly increased. English-Language and FrenchLanguage specialty, pay and pay-per-view services revenue ${ }^{5}$ increased 10.8 percent and 10.7 percent (CRTC, 2003: 55-61).

At the same time, Canadian Content Regulations have fulfilled their purpose of providing Canadian programming. An environmental scan of the Canadian television industry concludes that the supply of Canadian programming has increased approximately 23 percent over the past 6 years (Wall Communications, 2003: 4). ${ }^{6}$

Yet, despite the achievement of these policy goals, the Canadian broadcasting system as a whole is not "healthy and viable." In fact, concerns that the Canadian

\footnotetext{
${ }^{5}$ Specialty television services have a dual revenue stream -- advertising and subscription. PPV television services only have one source of revenue - subscription.

${ }^{6}$ This increase is mainly due to the CRTC licensing of new specialty and pay services, all of which are required to broadcast specific levels of Canadian Content.
} 
broadcasting system is in crisis are increasing. According to the CRTC, "a healthy and successful Canadian broadcasting system must include popular dramatic programs that reflect Canadian society and project Canada's stories onto the world stage" (2003-54:2). Furthermore, the report continues, "...drama should be a cornerstone of the Canadian broadcasting system. Drama can and should reflect Canadians of every background and culture to each other... It is through television drama that most Canadians participate in their national culture and share in the evolution of social values and stories of human passion." (CRTC, 2003-54: 1). However, Canadian drama has not been very successful at connecting with audiences. It has always struggled to maintain a place in the Canadian broadcasting system. For over 50 years, Canadians have been watching mostly television produced in the U.S. (CRTC, 2003-54:1). As a result, the "national culture and evolving values that Canadians have been exposed to on English-language television have been predominantly those of the United States" (CRTC, 2003-54: 1).

The amount of Canadian drama on Canadian television is low and is diminishing. At present, English-language Canadian drama cannot be found on the list of the "top ten" most watched programs in Canada (Appendix 1: Canada - Top Ten Programmes 1998 and Appendix 2: Canada - Top Ten Programmes 2001). ${ }^{7}$ More significantly, this is a situation exclusive to Canada. Most countries around the world always have at least one homegrown drama in their top ten (Dalfen, 2002: 41). ${ }^{8}$ Furthermore, of the time that Canadians spend watching television drama, only 9 percent is spent watching Canadian shows (Canadian Media Research Inc., 2003: 20).

\footnotetext{
${ }^{7}$ Weekly 'top tens' are published in Playback magazine and are supplied by Neilson media. BBM Canada also produces weekly top tens, which can be retrieved at their website.

${ }^{8}$ Appendix 3 illustrates domestic programmes as a percentage of the top ten programmes viewed in 1998 and 2001.
} 
Focusing on issues of economic viability and access to Canadian content led the government down a path which neglected the most crucial part of the broadcasting system: the audience, its citizens. These policies do not directly address the key role that Canadians as the audience play in maintaining a healthy and viable broadcasting system. Although these policies profess to be in the best interests of Canadians, their preoccupation with balancing the tensions of a public and private system have led policy to overlook cultivating a healthy Canadian audience for Canadian programs. Thus, as McQueen (2003) notes,

"it is hard to reconcile the reality of our viewing with the objectives of the Broadcasting Act, which through all its many versions, has insisted that programming respond to the tastes and interests of Canadians. Drama is the most appealing form of television for most Canadians. If they are not watching Canadian drama, it is hard to see how the Act is being upheld" (12).

How can the government expect to sustain a healthy and viable broadcasting system without considering the audience? If Canadians are not watching Canadian television, can the government really claim that a Canadian broadcasting system even exists?

Thus, despite the economic success that broadcasters are enjoying, and the increasing availability of Canadian programming, there is a component missing from the policies that the government has implemented. That component is Canadians. 


\section{The Crisis in Canadian Drama and English-Canadian Star System}

By the end of the 1990 s there was no denying that the Canadian broadcasting system was facing a crisis. The amount of Canadian drama on Canadian television was at its lowest level ever with no reprieve in sight (Appendix 4: Summary of Drama and Comedy Program Hours Broadcast During Peak Viewing Hours). As a response to this situation, the government began to rethink the Canadian audience and the role it played in the Canadian broadcasting system. The first significant shift in policy began in 1998 with the Canadian Television Policy Review. In its policy review, the CRTC posted a call for comments on the key issues and concerns and posed the following question; "What role should independent producers, program distributors and broadcasters play, respectively, in the promotion of Canadian programs? How can these sectors work together to ensure that Canadian programs are well-promoted at home and abroad?" (1998-44: 16).

In response to this question and Canadian viewership in general, the Canadian Association of Broadcasters (CAB), stated that the "ultimate measure of success is audience. If there is no audience for what we do, then nothing else matters" (1998, TV Board Submission: 5). The CAB's response suggests a shift in the thinking of policy in Canadian broadcasting. The idea of an English-Canadian star system appears in this report. The $\mathrm{CAB}$ suggests that the key to a successful Canadian broadcasting system is promotion, and, by extension, an English-Canadian star system (1998, TV Board Submission: 63). The CAB further notes that despite the millions that Canadian broadcasters invest into promotion, an English-Canadian star system has been halted by:

- the dearth of promotional venues such as Entertainment Tonight, David Letterman and Jay Leno; 
- the spillover across our borders of the American pop culture publicity machines promoting US celebrities, TV programs and films;

- the reluctance on the part of the Canadian media to promote Canadian personalities;

- the limited number of Canadian stars; and

- the lack of interest and/or cynicism of Canadians towards such promotion (CAB, 1998, TV Board Submission: 63).

Concluding, the $\mathrm{CAB}$ notes that the development of a star-system is not an overnight affair. It takes time and patience to change Canadian's and private industry's attitudes toward Canadian content (1998, TV Board Submission: 63-64).

Following the CRTC hearing for the Canadian Television Policy Review, the $\mathrm{CAB}$ reiterated its belief that an English-Canadian star system should be a new focus for broadcasting policy. "A fully-developed star system in English-Canada will help drive up viewership of Canadian entertainment programming. A recognized constellation of personalities helps build audience awareness for a program, creates a comfort level with 'familiar' faces, and contributes to increasing the size of the audience for a given program" (CAB, 1998, Final Comments: 49). The CAB's final recommendations to the CRTC listed the following as required components to help create an English-Canadian star system:

- increased exposure of our stars through program vehicles and new services, e.g. counting programs that promote Canadian programs and stars toward any exhibition requirements in the underrepresented area and launching new Canadian services, such as Star TV, that specialize in this area; 
- increased promotion of Canadian shows, e.g. creating an incentive to increase spending in the promotional area by permitting third party advertising costs to count toward any expenditure obligations; and

- an integrated strategy with the Canadian magazine industry, e.g. working with magazine publishers to promote Canadian stars and develop greater awareness amongst Canadians (CAB, 1998, Final Comments: 49-50).

Adamant in the view that a star system was the best means for success in Canadian drama, the CAB called on the CRTC to begin a "pan-industry task force" that would work on identifying the key elements needed for a star system (CAB, 1998, Final Comments: 50).

In response to public hearings for the Canadian Television Policy Review, the CRTC stated in its 1999 Television Policy that,

Audiences for English-language Canadian entertainment programs are lower than those for either foreign programs or Canadian French-language programs, in part because viewers are unfamiliar with the programs and their stars. In French Canada, a well developed "star system" promotes new programs and acting talent through all media. In contrast, the pervasive promotion of U.S. television shows and stars through foreign and Canadian media often means that English-speaking audiences are more familiar with programs and stars from Hollywood and New York than those from their own country (CRTC, 1999: 14-15).

The CRTC included entertainment-magazine programs in its list of priority programming (CRTC, 1999: 15). The goal was to make English-Canadians more aware of their 'stars' and therefore create a demand for Canadian television drama. 
Immediately following the implementation of the CRTC's 1999 TV Policy, there was very little discussion about a star system. However, three years later, the state of Canadian drama had not improved. In fact it was worsening (Appendix 4: Summary of Drama and Comedy Program Hours Broadcast During Peak Viewing Hours). Thus, in 2003, there was a renewed interest in Canadian drama and the notion of an EnglishCanadian star system was revisited.

The discussion of a star system was re-addressed in a report by the Coalition of the Canadian Audio-visual Union (CCAU) entitled "The Crisis in Canadian EnglishLanguage Drama" (2003). The CCAU note the challenges that face the development of a star system in English Canada:

...we cannot match the huge promotional machine that washes over Canadian households from the U.S. media. Whether it is on Entertainment Tonight, Viacom's nightly entertainment magazine show, on People Magazine, AOL Time Warner's monthly celebrity magazine, on the Tonight Show with Jay Leno, NBC's late-night talk show, or on many other U.S. outlets, the stars of U.S. television drama are constantly being promoted, crosspromoted, and talked about (CCAU, The Crisis in Canadian English-Language Drama, 2003: 23).

The CCAU report also noted that some support mechanisms for a star system are in place, citing shows like $e$ Now on CTV and the Mike Bullard Show on Global. ${ }^{9}$ Yet, in conclusion, the CCAU suggested that these tools cannot alone create a star system, and that, considering the dominance of the U.S. star system, it is difficult to compete (CCAU, The Crisis in Canadian English-Language Drama, 2003: 23).

\footnotetext{
${ }^{9}$ Since then, Global has cancelled the Mike Bullard Show.
} 
Despite its pessimistic view of the prospects for an English-Canadian star system, the CCAU recommended a 'co-ordinated strategy with co-operation from all':

Any solution to the crisis in English-language Canadian drama should involve input from all the affected stakeholders, and involvement by all of them in any solution. Among the stakeholders that need to be involved are the following: the Canadian Broadcasting Corporation, the National Film Board, the private conventional broadcasters, the pay and specialty licensees, the Canadian Television Fund and other funding agencies, the producers, the professional associations representing the creative community, and representatives of viewers and the public" (CCAU, The Crisis in Canadian English-Language Drama, 2003: 27).

Private stakeholders were not alone in their concerns about the continuing decline in Canadian drama. The CRTC and Telefilm commissioned a series of reports that reiterated the notion that an English-Canadian star system could help resurrect Canadian drama. In Trina McQueen's Report Dramatic Choices (2003; commonly referred to as the McQueen Report), she outlines steps that would help broadcasters create and promote Canadian drama. McQueen suggests that ensuring a future for Canadian drama can only be done through audience-building. She states five essential tools for audience-building: political will, funding, shelf space, broadcaster incentives and finally, star building and promotion (2003: 18).

Most of these recommendations were nothing new. Funding, access, and incentives have been the main mechanisms of cultural policy for decades. However, the last recommendation, "star building and promotion" was a departure from previous rhetoric in cultural policy. McQueen recognized that old mechanisms were not enough, 
that the success of Canadian drama depended on winning and keeping audiences, and that the way to do this was to increase promotion for drama stars and drama programs. Although the idea of "star promotion" seemed innovative, the way in which McQueen proposed to implement it fell within the previous parameters of cultural policy. According to McQueen (2003) "star building and promotion" could be done by expanding expenditure rule issues, regulations and programming credits (24). Therefore, although the 'idea' was innovative, the process by which McQueen proposed to build a star system was problematic. The recommendation as presented assumed that the development of a star system could be done by broadcasters alone. However, this was a gross simplification of how star systems operate.

In this same series as the McQueen Report, Guy Fournier (2003) commented on French-language drama, and suggested the reason for its success was the FrenchCanadian star system. He traced the history of French-language drama from its beginnings and the development of television in Quebec. The Quebeçois immediately recognized the political and cultural importance of developing and maintaining a broadcasting system (Fournier, 2003: 9). From the beginning of television in Quebec, there was support for its stars. Talk shows became a key factor, giving audience exposure to the actors, writers and directors of French Canadian television (Fournier, 2003: 10). McQueen's proposal neglected to address this factor.

In November 2003, the CRTC received comments on its drama reports from stakeholders across the broadcasting industry as well as individuals. In all the CRTC received 300 submissions. Very few seriously considered the role of the star system. ${ }^{10}$ If

\footnotetext{
${ }^{10}$ Responses reviewed include submissions from the CBC, CCAU, CAB, CFTPA, and Friends of Canadian Broadcasting.
} 
the star system was mentioned at all in the submissions, it was only in relation to the economic incentives developed in the McQueen Report (2003). Only one submission moved beyond this discussion and again raised the issues of a star system.

The CAB, as in its earlier reports (1998, TV Board Submission, and Final Comments), restated its position that the development of a star system was crucial. The $\mathrm{CAB}$ again reaffirmed that a cross-media initiative was needed. Noting the success of the Quebec star-system, the CAB concluded that cross-media promotion was critical for building audiences (2003: 24). The CAB also supported the initiative taken by the CRTC with respect to priority programming and suggested that entertainment news programs should continue.

The CRTC should allow "star system" entertainment magazine programs aired outside prime time to claim either: 50 percent priority programming credit; or 125 per cent credit against daytime Canadian content credits. The CAB Television Board believes this proposed incentive could make a positive contribution to the building of a Canadian "star system" in English Canada... The CAB Specialty and Pay Board are supportive, in principle, of incentives that will encourage the creation of a star system for Canadian drama (CAB, 2003: 27-28).

Although the private sector acknowledged the difficult task of competing with the American entertainment industry, it also recognized the benefits that an EnglishCanadian star system would provide.

In June 2003, the Standing Committee on Canadian Heritage, in its Report Our Cultural Sovereignty: The Second Century of Canadian Broadcasting, reiterated the importance of the star system. This report confirmed the belief that a star system was a 
key component in a healthy broadcasting system. Although the report was on the Canadian broadcasting system as a whole, the section on programming was quick to note that not much emphasis was placed on French-language programming. "It is not that French-language programming is without its challenges...however the top 20 shows are always Canadian-made" (Our Cultural Sovereignty, 2003: 120-121). The report stated that in the mid-1980s French-language broadcasters reaffirmed their belief that "the way to break the dependence on American programming was through a star system and to produce programming which would permit French-speaking Canadians to see their stories and their communities" (Our Cultural Sovereignty, 2003: 121).

The report reaffirmed the shift in approach to broadcasting policy. The government could no longer ignore the crucial role that Canadians play in the success of the broadcasting system. As a result, the Committee stated, "it will take steps to align its regulatory and funding mechanisms so that they place stronger emphasis on attracting audiences to Canadian programming. In particular, the Government believes that real strides in viewership for English-language drama need to be made" (Our Cultural Sovereignty, 2003).

By 2003, then, the relationship between audiences and a successful Canadian drama industry has become a central focus of cultural policy. Two of the largest government funding agencies for Canadian drama, Telefilm Canada and the Canadian Television Fund (CTF), acted on this new priority by implementing "audience-based" funding strategies. In 2003, the CTF announced new criteria that would ensure "funding be directed to productions that stand the best chance of attracting Canadian audiences" 
(CTF, 2003: 1). Telefilm has also adapted its guidelines to support more commercially oriented productions.

As policy-makers move ahead with their audience-based strategy to 'fixing' Canadian drama, it is even more crucial that we explore the complexities of celebrity culture. Yet, aside from the recommendations in the McQueen Report (2003), Fournier's (2003) history of the French Canadian star system, and the CAB's recommendations for a star system, little thought has been given to the current status of Canadian celebrity culture and the plausibility of creating an English-Canadian star system.

The central discussion about how to support a star system over the past year has been limited to the subject of incentives and expenditure credits that would encourage broadcasters to increase the level of promotion for Canadian drama. Limiting the discussions in such a way almost guarantees that an English-Canadian star system will not fully develop. As the $\mathrm{CAB}$ stated numerous times, a star system involves numerous components.

As a result there is a critical gap in public discussion of an English-Canadian star system. The success of an English-Canadian star system depends upon a thorough understanding of star systems and the people who make up these systems. To facilitate such an understanding, we must first explore the nature of celebrity-making. The following chapters will assess what is necessary to develop and maintain an EnglishCanadian star system. 


\section{CHAPTER 2:}

\section{KEY ELEMENTS OF SUSTAINABLE CELEBRITY}

Contrary to popular belief, celebrity is not a twentieth century North American phenomenon. ${ }^{1}$ Although the term 'celebrity' was not widely used until the 1920 s, a form of celebrity culture existed prior to this time. Likely all societies have had some form of fame and recognition for favoured members. However, what defines modern-day celebrity is visibility (Rein, 2003).

Visibility does not only refer to visual representations of the celebrity, it more broadly refers to the celebrity's overall presence in society. A celebrity presence must be established through a variety of media, including radio, television and print. The four key elements of this visibility complex are: geographical reach, ease of access, an illusion of intimacy and news-worthiness. Each of these components needs to be present for celebrity to be sustained. A critical aspect of a celebrity's visibility is their reach. The celebrity's visibility must be able to transcend regional geographical borders to the national level. It could be argued that if one is considered a celebrity, one has already obtained significant visibility. However, Rein (2003) suggests that there are different levels of visibility, which in turn determine the success of a celebrity. Rein refers to this as the 'Visibility Reach Pyramid'. Rein suggests there are 5 levels of visibility: invisible, local, regional, national and international (93-94). The levels of this pyramid indicate the 'well-known-ness' of the celebrity. Rein uses the term 'memory lock' to denote the achievement of celebrity through visibility. In this state the celebrity is remembered by

\footnotetext{
${ }^{1}$ The majority of the literature on celebrity traces its twentieth century development in only the United States, creating the impression that it is a modern American phenomenon. Richard Dyer's (1998) account of the star system, which begins with the development of Hollywood, is a case in point.
} 
an audience with ease and associated with certain characteristics that foster a sense of familiarity usually found only in personal relationships. Quite often in celebrity, a name may 'ring a bell' or 'sound familiar'. However, the goal is to move beyond mere recognition into a state where the celebrity's name and image are so familiar that the potential audience member feels they know the celebrity personally. This is what Rein (2003) refers to as memory lock.

Rein's definition of each level is somewhat self-explanatory, however, clarification is warranted. In part he is concerned with the extent to which celebrity is generated by visibility maintained over time. "Invisible" does not mean that the celebrity does not have visibility; rather, it indicates a visibility so limited that it tends not to register with audiences (Rein, 2003: 92). An example of this level would be persons who receive 'fifteen minutes of fame'. During their fifteen minutes, they would have a substantial amount of visibility; however, it lacks staying power, and they would be quickly forgotten. In contrast, celebrity sustained over time helps achieves 'memory lock,' the celebrity is deeply inscribed into the memories of audience members.

Another key part of celebrity is its geographical reach. Local visibility is achieved by politicians, athletes and other notable locals (Rein, 2003: 95). These celebrities are well-known within limited geographical boundaries; however, their visibility rarely transcends these local neighbourhoods.

Similar to local visibility, regional visibility is also measured geographically. However, with regional visibility the celebrity is more widely known. Rein notes that even with regional visibility, celebrities are still only visible within their sector (Rein, 2003: 97). For instance, politicians are known only in politics or business executives are 
known as celebrities only by other business executives. Obtaining memory lock in this level is more difficult, as there is more competition.

National visibility is the lowest level on the pyramid that a celebrity in the entertainment sector would hope to achieve. When a celebrity reaches the level of national visibility, Rein (2003) suggests that a celebrity can obtain visibility across sectors (97). It is difficult to sustain this level. For most celebrities, sustaining memory lock becomes an on-going process, dependent upon visibility being constantly maintained at that level. Very few celebrities can maintain memory lock with their audiences without constant visibility. The celebrities that do, would be considered 'super-stars' (for instance, with Bob Hope or Julia Roberts, we do not need a constant flow of information to know who they are).

The highest level in Rein's Visibility Reach Pyramid is international and is the most sought after. Advances in communication technologies have increased the celebrity's ability to achieve international visibility, yet it remains the most difficult level of visibility to obtain. Entertainment celebrities have an advantage in achieving this level, since their images are often exported via media productions. However, international celebrities must compete with a large number of other international and national celebrities.

Regardless of the level of visibility that a celebrity is acquiring, it is their ability to maintain visibility that determines their success. Memory lock remains the goal. They must ensure, despite their visibility reach, that this visibility is ongoing. Memory lock through visibility becomes the key to a successful star system. A celebrity requires a ubiquitous and continuing media presence. 
The audience needs to be constantly fed information on the celebrity until memory lock has occurred. In a society where we are constantly inundated with celebrity images, it is critical that a celebrity is constantly exposed to his or her potential audience. With so many celebrities to follow, an audience can quickly forget one celebrity while focussing on a number of others. Thus it is important that the audience is always given access to the celebrity. Potential audiences will not seek out an aspiring celebrity. Even if a celebrity has memory lock, the audience still needs a certain amount of access to the celebrity to keep the celebrity relevant.

Although there is a saying that "any publicity is good publicity", for successful celebrity, how the celebrity is seen by its audiences is just as important as how often. The relationship between the celebrity and the audience is a key component of visibility. In this element, then, it is not only that the celebrity be seen, it is how the celebrity is seen that is significant. An audience is likely to lose interest in a celebrity if he or she is constantly portrayed as different. The connectivity between the audience and celebrity allows the audience to see the celebrity as 'real'. The audience must be able to empathize with the celebrity. This empathy creates loyalty and demand for the celebrity.

The final element of the visibility complex is newsworthiness and is again concerned with how the celebrity is seen. Celebrities need to be regarded as important in society. Linking celebrities to the issues of the day creates a sense of importance for the audience. This component is also key to the roles that the celebrity can then play within the star system. The more important we believe a celebrity to be, the more credibility and trust we place in that celebrity. The more trust we place in the celebrity, the more power they hold within society. 
From the above discussion, it is clear that the key element to creating and maintaining celebrity is visibility. Furthermore, there are many components that are factored into the visibility of the celebrity; notably geographical reach, ease of access, the 'illusion of intimacy,' and news-worthiness. When any one of these elements is missing, celebrity as it is experienced in its modern form does not exist.

\section{Fame before Celebrity}

It is possible to trace the development of celebrity in three periods: PreHollywood celebrity, Early Hollywood celebrity and Post-Hollywood celebrity. It is beyond the scope of this chapter to present a historical analysis of the development of celebrity. However, it is helpful to highlight key characteristics in the development of celebrity in various historical periods. Emphasis will be placed on the Early Hollywood and Post-Hollywood periods.

Before celebrity as it is known today existed, fame did exist and was guarded and controlled by society's elites. Celebrity as experienced in Roman civilization illustrates how celebrity was guarded and controlled. Braudy (1986) suggests fame was significant because the Roman religion did not have a well-developed concept of an afterlife. Thus the only way to live "after death" was through fame (60). Such fame was highly sought after (Braudy, 1986: 58). Gamson (1961) described the ways in which fame was attained. There was fame which acknowledged and celebrated "public action" that was "for the good of the state" (Gamson, 1994: 17). Fame could also be achieved through wisdom or religion. Fame of wisdom, Gamson suggests, came to those people who were 
known for being knowledgeable or literary (1994:17). Religious fame was considered to be "fame of the spirit or the being" (Gamson, 1994: 17).

These types of fame would allow for a variety of famous people; yet there were some major limitations to achieving this fame. In this era, fame was restricted to the persons who already held power within society. As Gamson (1994) and Braudy (1986) suggest, it was the political and religious elites who controlled public images. ${ }^{2}$

In this era, fame was limited by the means of communication that were available. Oral and written forms of communication had a limited capability to conquer space and time. Images were transmitted more slowly then they are today, so it took more time for fame to spread.

\section{Pre-Hollywood Celebrity}

The Pre-Hollywood period of celebrity was characterized by the availably of mass communication commodities but their limited impact and use. This resulted in a celebrity that had some reach and accessibility but little illusion of intimacy. The copper coin is an example of a new commodity in this period. The mass production of copper coins allowed for the widespread circulation of political images. Previously only the possession of the rich, such images became a medium of more general cultural exchange (Braudy, 1986: 266). Yet, the copper coin did not contain much information. Although a face could be recognized, very little information could be transported alongside (Gamson, 1994: 17). This limited the ability to create a sense of intimacy between the celebrity and

\footnotetext{
${ }^{2}$ Although this paper has not used the Bible as an example, the popularization and celebration of religious figures is another case in point. Religious elites and political figures promoted the bible, but simultaneously limited its accessibility. For example, the bible was only available in Latin — a language spoken by elites and religious figures.
} 
the masses. To achieve celebrity as it is experienced in the modern period, the picture alone was not enough; context via text was necessary as well. ${ }^{3}$

Regardless of its limitations in this early period, the promotion of the image was a crucial component in the development of celebrity culture. However, individual personality could not be adequately transmitted with the forms of media available. As the next section highlights, individuality is a key component of celebrity. It produces "the illusion of intimacy," which Schickel suggests is the key ingredient of fame and celebrity (1986: 45).

\section{Early Hollywood Celebrity: Setting the Stage for Celebrity Culture}

Like the Pre-Hollywood period, the Early Hollywood Celebrity period is characterized by the emergence of new technologies. However, these technologies had more reach and more accessibility. Consequently, this is the period when the illusion of intimacy is first created. It is also in this period that the tools of the current period of celebrity, such as the tabloid and the fan magazine, emerged.

Although many scholars identify the development of the star system with the development of Hollywood, the American star system actually developed in the theatre. McArthur (1984) argues that the star system developed in the 1820s when theatre companies began employing performers in the same role across the country (9-10). Ponce de Leon (2002) suggests that the star system developed in the 1840s when promoters and theatre managers realized that press coverage of entertainers would arouse

\footnotetext{
${ }^{3}$ It is interesting to note also that a shift occurred in the artistic world. Whereas prior to this period, the focus of art was religious imagery, there begins to be a focus on 'individual faces' (Braudy, 1986: 266).
} 
interest in their performances (207). By the late $19^{\text {th }}$ century, American theatre embodied key elements that would later merge in the Hollywood star system.

As Schickel (1986), Ponce de Leon (2002), Dyer (1998) and deCordova (1990) suggest, the emergence of the current celebrity culture is closely linked with the development of new communications technology. Boorstin (1961) refers to this as the 'Graphic Revolution', the spread of new technologies - printing, photography, moving pictures, and television - that allowed for the preservation, transmission and widespread diffusion of information and images. They suggest that it was the in the $1920-1930$ s, when mass media began to dominate, that the modern celebrity system began to emerge. From this point on, there was little doubt about the power of the popular media in producing and distributing information (Turner, Bonner and Marshall, 2000: 7).

The American system of production and consumption created ideal conditions for celebrity and stardom. A core American value is social mobility, the belief that anyone could be a success, perhaps even a star (Alberoni, 1972: 26). However, much like 'fame' in the Roman Empire, theatre celebrity was restricted by limited communications technology. Thus the majority of literature on celebrity links the emergence of celebrity to Hollywood and the development of mass communication.

\section{Journalism}

Ponce de Leon (2002) notes that as urban populations grew, so too did inexpensive newspapers directed at a broad, cross-class audience. The popular press was a primary form of intra-urban communication (Ponce de Leon, 2002: 30-31) at the centre of a quickly expanding public sphere. This medium was able to have a reach that previous technologies were unable to achieve. The mass circulation press allowed a 
growth in human-interest journalism, including journalism that focused on 'private lives' (Ponce de Leon, 2002: 41).

To do this, journalism looked for ways to make people to seem more 'real' (Ponce de Leon, 2002: 41). Advances like the photograph aided the illusion of intimacy. The photograph, like the printed word, could be reproduced quickly and distributed widely. Hamilton and Hargreaves (2001) go as far to suggest that it was the photograph in the $1840 \mathrm{~s} / 1850$ s that helped to create the "cult of celebrity" (19). They propose that through photography the essential relationship between celebrities and image-makers was established (Hamilton and Hargreaves, 2001: 19).

However, the most crucial aspect of the photograph in journalism was that it "did not only provide a name, it provided a description of a stranger with a realistic image and it was at nearly everyone's disposal"' (Gamson, 1994: 20). A caption soon became a standardized part of the photograph. It also became common for a short profile to accompany a picture (Ponce de Leon, 2002: 62). These profiles could provide more information than those widely distributed commodities of the pre-Hollywood period. These advancements in printing and photograph allowed for the transmission of information alongside a picture, something the copper coin could never accomplish. ${ }^{4}$

In this period a new form of journalism emerged: celebrity journalism. It began as human-interest journalism, such as small gossip columns which highlighted the social activities of a city's 'elite'. As they grew, they developed into larger 'interview columns'. At the same time these 'elites' (as they were referred to) were beginning to make their way into other sections of the paper, such as the fashion section (Ponce de

\footnotetext{
${ }^{4}$ New forms of mass media offered intimacy, or as Schickel has suggested "the illusion of intimacy" (1986: 45).
} 
Leon 2002: 49). In these articles, the celebrity (as they were now called) was used as an example of the newest trends (Ponce de Leon, 2002: 49).

Soon, 'profile or sketch' columns of celebrities were employed in one of two ways: for a behind the scenes tour or a home tour (Ponce de Leon, 2002: 49). What they offered was not an in-depth story about the glamorous life of the celebrity, but rather a 'behind the scenes' look at the celebrity's 'real life' daily routines (Ponce de Leon, 2002:64). The profile or sketch would always be accompanied by a photograph of the celebrity in this 'real life' environment (Ponce de Leon, 2002:64). This gave the reader a sense of familiarity or intimacy with the celebrity.

Film-Close Ups

At the same time that celebrity journalism was emerging, there were also significant advances being made in the film industry. New techniques in film, such as the close up, allowed for greater recognition of individuals within the film and thus the illusion of intimacy was easily achieved. (Schickel, 1986: 46-47).

The public demanded information on all aspects of the star's existence outside of the film, including such trivia as hobbies, apparel and romantic life (deCordova, 1990: 98). The film industry soon recognized that it should employ other forms of mass communication to satisfy this demand. It used the print media, specifically the emerging tools of celebrity journalism -magazines and tabloids.

\section{Magazines}

In 1910 the first 'movie' fan magazine, Photoplay, was founded. Soon a variety of other fan magazines emerged (Gamson, 1994: 25). Other magazines also contributed to celebrity culture. For example, Turner, Bonner and Marshall (2000), suggest that 
woman's magazines were a key player in celebrity-making (116-117). Indeed, the heavily illustrated woman's magazine, they contend, was the perfect location for celebrity journalism. Women were the primary consumers of both the celebrity culture and the consumer goods advertised within the pages of these magazines. Celebrity fit well with consumer capitalism: it sold magazines and movies directly while indirectly selling the other products advertised in the magazines. Magazines were filled with pictures and stories of the celebrities most in demand. Product (the movies) in one media had become subject in another, creating a mutually beneficial cross media promotional process.

\section{Tabloid}

The tabloid magazine was another important tool for celebrity culture. Some (Turner, Bonner and Marshall, 2000 and Schickel, 1986) argue that tabloids, although despised by celebrities, are a significant means of maintaining their celebrity. Similar to the magazine (example: fan or women's) the power of the tabloid lies in its use of illustrations (Schickel, 1986: 67). Tabloid magazines survive off the exclusive photos they claim to have of the celebrity. Their covers are full of intriguing photos of celebrities. The celebrity is far from being glamorised in this media. Tabloids provide the other side of the celebrity, which is also what we desire.

What these 'bad' photos do for celebrity culture is to create discussion, or rather, gossip. As Schickel (1986) notes, gossip intensifies the relationship between the celebrity and his or her audience (22). The celebrity needs to remain in the foci of the media. Although the celebrity has a love-hate relationship with the tabloids, there is no denying the importance that they play. 
When television emerged in the 1950 s, broadcasters promoted the stars of their shows as much as they could through the various facets of celebrity media. In Quebec, for instance, stars were promoted through other types of programming, like talk shows (Fournier, 2003: 11). The development of a variety of forms of mass communication in the twentieth century increased the possibilities for cross media promotion.

The entertainment industry has fostered the development of a celebrity system that allows newspapers and magazines to have a ready supply of local content and the television networks to have successful public events populated with their own developed personalities and a ready-made system to fabricate celebrities from news and current affairs (Turner, Bonner and Marshall, 2000: 160).

As celebrity culture expanded, so did an industry that would cater to the celebrity. This industry employs publicists, managers, agents and celebrity journalists of the stars. The development of this industry links itself to the development of the Hollywood star system.

\section{Post-Hollywood Celebrity}

The Post -Hollywood Celebrity period is the modern-day celebrity system. It is characterized by a vast reach, access and illusion of intimacy. What differentiates this period form the Early Hollywood period is that the media are no longer simply maximizing an existing demand for celebrity news and culture, they have in themselves the power and inclination to manufacture celebrity. This period began in the mid-1950s. The key tools of a celebrity culture had been established and advances in photography, 
printing and film (and broadcasting) allowed for a continual flow of information to audiences. Demand for celebrity content reached its zenith. Celebrity journalism had grown into an industry bigger than the newspaper in which it began.

At the close of the twentieth century, celebrities were everywhere, to the point that being a celebrity was almost commonplace. The question then became how to ensure 'memory lock' (80). It was no longer enough to simply release information to the mass media and let them perform their magic. Attaining celebrity now required a perfectly executed strategic marketing plan.

\section{Manufacturing Celebrity}

According to Rein (2003), celebrity is no longer created by accident or overnight. Rather celebrity development must be understood in terms of a strategic marketing process. "Most aspirants achieve high visibility not as a result of irrepressible talent or accident, but rather because of a strategic marketing process" (Rein, 2003: 61). Although Rein does note that some people naturally have the qualities that audiences seek, most do not, and therefore celebrity must be actively pursued (2003: 62). Celebrity is like any other consumer product. "The marketing of celebrities involves four major steps: market analysis, product development, distribution, planning and a promotion strategy" (Rein, 2003: 68).

Involved in this marketing of the celebrities are their publicists, managers and agents. The aim of these people is to control and maintain the image of their 'contracted' celebrity. "The role of the manager, the network publicist, the publisher's publicist, or the agent includes strategic use of the media to build and shape a career, to generate box 
office, to excite public interest, to disseminate information and so on" (Turner, Bonner and Marshall, 2000: 93). It is not the celebrity who holds the power within the media; it is their representatives. The celebrity is then shaped according to how their publicist wants him or her to be shaped. They control the flow of information. Information about celebrities is almost always strategically placed for the consumers' consumption (Turner, Bonner and Marshall, 2000: 4).

However, these are not the only gatekeepers of celebrity image. The individual television networks play a significant role in the marketing of their celebrities. This is what Turner, Bonner and Marshall (2000) call "in-house promotion' (85-86). It is also a perfect example of 'media feeding media' (Turner, Bonner and Marshall, 2000: 85-86). In this situation one of the most powerful agents is the network publicist, who has the power to determine what information will be fed to the outside press (Turner, Bonner and Marshall, 2000: 87). What the gatekeepers of celebrity image are constantly seeking is visibility.

To conclude, the element of visibility and its components are crucial for the functioning of celebrity and by extension the star system in any society. As this chapter discussed, the idea of celebrity existed long before Hollywood, however, pre-Hollywood celebrity was limited in its ability to achieve visibility, in either reach, accessibility, the ‘illusion of intimacy' or new-worthiness. Advances in communication technologies removed these limitations just as the Hollywood studio system was emerging, thereby allowing the key tools necessary in the production of celebrity to develop.

This chapter suggests that a star system can be manufactured. It is not only in the U.S that the industry has actively been promoting a star system. In Australia, for 
example, it was not that long ago that American celebrity and culture dominated the media. Frustrated with this situation and a continual decrease in homegrown production, Australia, using the mechanisms of celebrity making, was able to create national celebrities. Turner, Bonner and Marshall (2000) attribute this growth in national celebrity to an increased focus on celebrity by the news-media in Australia. The Australian example reinforces the discussion in this chapter which suggests that celebrity can be developed through a conscious and co-ordinated strategy. In other words, celebrity making is a process that is amenable to government cultural policy. 
PART II 


\section{CHAPTER 3:}

\section{CELEBRITY IN ENGLISH-CANADIAN PRINT MEDIA}

With the contextual information provided in Part I, it is now possible to move on to the case study of English-Canadian celebrity. As the previous chapter outlined, the visibility complex (reach, ease of access, the 'illusion of intimacy' and news-worthiness) provides a checklist of key characteristics for a successful star system.

Given the premise that the visibility complex is critical to the production of celebrity, the question that next needs to be explored is; "how visible are EnglishCanadian celebrities?" There are many media tools of celebrity production - print, television, radio and publicity agents, etc. - however, this study deals with only print. To discover what needs to be done to foster an English-Canadian star system, we will proceed to analyze Canadian news media in print as a cultivator of English-Canadian celebrity. News media in print were chosen since previous studies (Ponce de Leon, Turner, Bonner and Marshall) in celebrity have indicated that news media, particularly those in print, are crucial tools in the development of celebrity.

The purpose of the following two chapters is to compile information on the treatment of celebrity in English-Canadian print media and to analyze it to see how it can be used to guide policy directed at developing an English-Canadian star system. To this end the author compiled data on the coverage of seven Canadian celebrities in selected print media over a six year period (1998-2003). The print media sampled were the Halifax Chronicle-Herald, the Toronto Star, the Vancouver Sun and Maclean's magazine. 
The selected English-Canadian celebrities were Rick Mercer, Sarah Polley, Paul Gross, Cathy Jones, Mary Walsh, Nicholas Campbell and Sonja Smits.

This study focuses on print media because sources from an extended time period were readily available for research purposes and could be searched electronically. This focus has the further advantage of allowing ready comparison with other studies in the production of celebrity that have highlighted the importance of print media.

This chapter begins with an explanation of the methodology employed to develop the case studies that follow. A general overview of the research findings follows. Next comes more detailed analysis of individual celebrities' career paths and the media attention they attracted in the study period. The chapter concludes with a comparison of the research findings on the seven sampled celebrities.

Mechanics of the Case Study:

Seven Canadian celebrities were traced through three newspapers and one news magazine from 1998-2003. The following print media were selected:

- The Halifax Chronicle-Herald

- The Toronto Star

- The Vancouver Sun

- Maclean's magazine

The three selected newspapers were chosen to reflect Canada's diverse regions as well as its diverse media ownership groups. Maclean's, the only non-newspaper included in the study, was chosen because it was news oriented like the newspapers, yet national in its reach. Although this is not an exhaustive and comprehensive study of print media, it is 
representative enough to suggest broad patterns in English-Canadian celebrity coverage in print media. ${ }^{1}$

\section{Selection of Canadian Celebrity Subjects:}

The celebrities chosen had to be actors who work primarily in Canada. Since this thesis is concerned with Canadian celebrity culture, it would be irrelevant to choose a Canadian who achieved his or her fame through American productions and is currently living and working in the United States, thus participating in American celebrity culture. Therefore "Canadian celebrities" like Mike Myers, Jim Carey and Pamela Anderson are excluded since they are primarily located and working in the United States. In the interest of identifying characteristics of 'made in Canada celebrity', only Canadians who have remained primarily in Canada and are currently working in the Canadian television or film industry were selected for the study. Also, the selected celebrities are actors who within the timeframe of the case study, were in 'principal roles' (as defined by the Alliance for Cinema, Television and Radio Artists [ACTRA]).

This study is concerned with the correlation between television and celebrity, and is limited to television celebrities (although there is cross-over from film to television). The main criterion for the selection of celebrities is that they have had exposure over an extended period of time (years) on national Canadian television. In other words, these celebrities have had sustained exposure to audiences across Canada through the most effective celebrity-making medium, television. Using this criteria, the following celebrities were selected for the sample:

\footnotetext{
${ }^{1}$ It should be noted that English-Canada lacked the celebrity tabloid print media until after this study was conducted.
} 
- Rick Mercer

- Sarah Polley

- Paul Gross

- Cathy Jones

- Mary Walsh

- Nicholas Campbell

- Sonja Smits

\section{Categories of Analysis}

The units for this content analysis were print media articles that contained the name of one of the pre-selected Canadian celebrities. The articles were then categorized according to the amount of exposure they gave the celebrity and their subject matter. The resulting category system included: headline, lead line, illustration, name dropping, and content (industry, awards, celebrity profiles, events, politics and general interest). These categories were chosen as they suggest the type and extent of Canadian celebrity visibility in print media.

The purpose of the following analysis is to discover:

- Do Canadian print media complement television in providing the cross-media promotion critical to celebrity-making?

- Do Canadian media provide the kind of coverage that cultivates celebrity?

- Do Canadian media provide enough coverage to give Canadian television actors the visibility necessary for a sustained star system? 
- What are the variations in coverage from one actor to the next, from one print medium to the next, and what do they suggest about celebrity print media coverage in Canada?

\section{Overall Summary of Research Findings}

In total from 1998-2003 there were 1966 articles that mentioned at least one of the 7 Canadian entertainers from the 4 selected print media sources. The Toronto Star contained the most articles, 1014, followed by the Halifax Chronicle-Herald with 469 , and the Vancouver Sun with 454. Maclean's, with fewer but longer items per issue and fewer issues, had a total of 29 . The following chart breakdowns the overall findings.

Table 3.1

Summary of print media articles

\begin{tabular}{|l|l|l|l|l|l|}
\hline Total 7 Subjects & $\begin{array}{c}\text { Halifax Chronicle- } \\
\text { Herald }\end{array}$ & $\begin{array}{c}\text { Toronto } \\
\text { Star }\end{array}$ & $\begin{array}{c}\text { Vancouver } \\
\text { Sun }\end{array}$ & $\begin{array}{c}\text { Maclean's } \\
\text { Magazine }\end{array}$ & TOTAL \\
\hline Total \# Articles & 469 & 1014 & 454 & 29 & 1966 \\
\hline & & & & & \\
\hline Headline & 53 & 50 & 48 & 11 & 162 \\
\hline Lead Line & 71 & 89 & 56 & 24 & 240 \\
\hline Illustrations & 99 & 154 & 86 & 12 & 351 \\
\hline & & & & & \\
\hline Content: & & & & & \\
\hline Industry & 240 & 571 & 241 & 14 & 1066 \\
\hline Awards & 116 & 141 & 83 & 0 & 340 \\
\hline Personal Profiles & 16 & 37 & 19 & 13 & 85 \\
\hline Events & 34 & 84 & 25 & 0 & 143 \\
\hline Politics & 28 & 72 & 24 & 0 & 124 \\
\hline General Interest & 35 & 109 & 64 & 0 & 208 \\
\hline & & & & & \\
\hline Name Dropping & 377 & 910 & 360 & 6 & 1653 \\
\hline
\end{tabular}




\section{Headlines}

The headline is important in creating visibility as its physical characteristics demand attention from the reader. The headline is more likely to be distinctive from the standard text of the newspaper. In total there were $162(8.2 \%)$ headlines that contained the name of one of the research subjects. Maclean's ratio was the highest with $37.9 \%$ of its articles headlining the name of the celebrity. The Halifax Chronicle-Herald and the Vancouver Sun were slightly above the overall average with $11 \%$ and $10.6 \%$ respectively. The number of headlines in the Toronto Star was below average with only 4.9\%. It should be noted, however, that excluding Maclean's, the number of headlines from each paper including celebrity names was similar at around 50 each.

\section{$\underline{\text { Illustrations }}$}

Illustrations are perhaps one of the most visible aspects of the newspaper. Attention levels for illustrations and text accompanied by illustrations is the highest (Bogart, 1989: 316). Of the 1966 articles sampled, 351 (17.9\%) included an illustration of the corresponding celebrity. Maclean's averaged higher with $41.4 \%$ as did the Halifax Chronicle-Herald $(21.1 \%)$ and the Vancouver Sun $(18.9 \%)$. The Toronto Star averaged slightly lower with $15.2 \%$ illustrations. In most cases the illustration complemented the corresponding news article. However, there were a few exceptions when an illustration appeared with only a caption. 


\section{$\underline{\text { Lead Line }}$}

Besides the headline, the lead line is also a highly visible aspect of a news article. Patterns in newspaper reading suggest that a majority of readers will only read the first few lines of the article before moving on to another article (Bogart, 1989: 158). Positioning the celebrity's name within the lead line suggests a certain level of accessibility. The lead line of the news article is a more visible aspect of the article. In total there were $240(12.2 \%)$ occasions when the sampled celebrity names appeared in the lead line of the article. This was calculated regardless of whether the name appeared in the headline. Again, Maclean's ratio for lead lines, at $82.8 \%$, exceeded the average. The $\underline{\text { Halifax Chronicle-Herald was again slightly above average at } 15.1 \% \text {, and the Vancouver }}$ Sun matched the average at $12.3 \%$. Again the Toronto Star was below average with only $8.8 \%$

\section{Content}

Regardless of how or why a particular celebrity was used within the sampled articles, each article was categorized based on the content of the article in order to analyze how Canadian celebrities were framed within print media. As Chapter Four will discuss in more detail, the type of coverage is crucial to fulfilling the visibility complex.

\section{Content:}

\section{Industry}

As the largest category within content, 'industry' consisted of $1066(54.2 \%)$ of the sampled articles. Articles within this category had as their subject matter television and film production, non-policy broadcasting issues, audience measurement (BBM), casting 
information and entertainment briefs. This category also represents approximately $50 \%$ of the articles sampled from the Halifax Chronicle-Herald (51.2\%), the Toronto Star (56.3\%), Maclean's (48.3\%) and the Vancouver Sun (53.1\%).

\section{Awards}

This category represents $340(17.3 \%)$ of the 1966 sampled articles. This category included any article about an award and hence included such topics as the Geminis, the Genies, the Canadian Comedy Awards, the Giller Award, the Order of Canada, and the East Coast Music Awards (EMCA) among others. Articles detailing awards tended to be medium to long in length and were annual like the awards themselves. Excluding Maclean's, which did not have any articles in this category, the 'awards' was the second largest content category. In the Halifax Chronicle-Herald, 116 of the 469 articles were about awards (24.7\%). The percentage was lower in the Toronto Star $(13.9 \%)$ and in the Vancouver Sun $(18.9 \%)$.

\section{Personal Profiles}

One of the more significant categories in celebrity making is 'personal profiles.' These articles are similar to biographies, in that they trace an aspect of the celebrities' life (career or personal). This category included interviews and ranged in length and depth. Personal profiles accounted for 85 (4.3\%) of the 1966 sampled articles. Maclean's ranked the highest in this category with $44.8 \%$ of sampled articles being profiles. For the remaining media the ratio was significantly lower; $3.4 \%$ of the Halifax Chronicle-Herald; $3.7 \%$ of the Toronto Star and $4.2 \%$ of the Vancouver Sun. 


\section{Events}

Of the 1966 sampled articles, $143(7.3 \%)$ fell into the category of 'events'. This included articles discussing upcoming galas, banquets, festivals (film, television and comedy). Most of these articles were located in the "Events Listings" or an article promoting the upcoming event. In either case the celebrity was not the central focus of the article, but rather a footnote that he/she would be in attendance. Similar to the 'awards' category, Maclean's did not have any articles that fell within the parameters of this category. The Toronto Star led this category with $84(8.3 \%)$ of the 1014 sampled articles falling into this category. The Halifax Chronicle-Herald had 34 (7.3\%) 'events' articles and the Vancouver Sun had 25 (5.5\%) such articles.

\section{Politics}

Of the 1966 articles sampled 124 (6.3\%) were discussing political issues. The political issues varied from health (government aspect), environment, education, democracy and broadcasting regulation and funding. In these articles the celebrity content was fairly consistent; a name reference or illustration. The Toronto Star ranked highest in the politics category with $72(7.1 \%)$ of their articles discussing politics. Political issues occupied 6\% of the Halifax Chronicle-Herald and the Vancouver Sun (28 and 24 articles). The articles sampled in Maclean's did not fall within this category. 


\section{Miscellaneous / General Interest}

Content that did not fit into the above categories and did not appear frequently enough to warrant its own category was placed in this broad category. Topics included book reviews, memorials, personal profiles (of a person not included in this study), trivia questions, feminism and health (social aspects). This category represents $10.6 \%$ of the total articles sampled. The Vancouver Sun topped this category with 64 articles from its sample falling in this category (14.1\%). The Toronto Star sample contributed 109 articles of its sample (10.8\%) and the Halifax Chronicle-Herald contributed 35 articles $(7.5 \%)$. Maclean's did not contribute any articles to this category.

\section{$\underline{\text { Name Dropping }}$}

This category was useful as it suggests the extent of the celebrity exposure in general news articles. Of the 1966 articles samples, $1653(84.1 \%)$ were articles that referenced or referred to one of the celebrity names, even though the article was not primarily about the celebrity. An example of this category would be the following:

"The rules helped establish writers like Da Vinci's Inquest's Chris

Haddock and Twitch City's Don McKellar, and helped raise the profile of performers such as Da Vinci's Nicholas Campbell and Traders' Patrick McKenna." (Strachan, 2000: A17).

This passage is the only time that Nicholas Campbell is mentioned throughout the article. The subject of the article was not the celebrity, rather, the celebrity was referred to as an example to make a point. The majority of articles (excluding Maclean's) that contained the celebrities' names, fell into this category. The Halifax Chronicle-Herald, the Toronto 


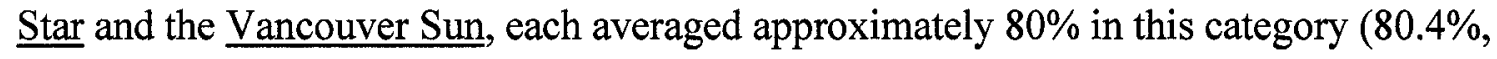
$89.7 \%, 79.3 \%$ respectively). Maclean's however, was dramatically below the $80 \%$ average with only $20.7 \%$ of the articles 'name dropping' the sampled celebrities. The majority of name dropping occurrences were located in articles that fell into the content categories of events, awards and industry. As Chapter Four will discuss, the results in this category have many implications for the visibility complex.

\section{Summary of Research Findings by Celebrity}

\section{$\underline{\text { Rick Mercer }}$}

Born in St. John's, Newfoundland on October $17^{\text {th }} 1969$, Rick Mercer has become one of Canada's best known television celebrities. Yet Mercer is still a newcomer to the world of television ${ }^{2}$. Like most aspiring actors, Mercer began his career in small venues and with small roles in Canadian films such as The Vacant Lot (1989), Understanding Bliss (1990) and Secret Nation (1992). However, it was his one-man shows: "Show Me the Button, I'll Push It;" and "Charles Lynch Must Die" (political rants on the Meech Lake Accord) in 1991 at the National Arts Centre in Ottawa that established Rick Mercer as key young figure in Canadian entertainment. These highly acclaimed shows eventually led to another series which critiqued the Mulroney Administration "I've Killed Before; I'll Kill Again" and "A Good Place to Hide" in 1995. In 1994, Mercer's "rants" landed him a role on CBC's "This Hour has 22 Minutes" news satire show and eventually a place in Canadian television history.

"This Hour has 22 Minutes" catapulted Mercer into the status of a Canadian icon of satire and comedy. Expanding on his role in "This Hour has 22 Minutes", Mercer

\footnotetext{
${ }^{2}$ For the complete filmography of each celebrity please see Appendices 5 - 11 .
} 
went on to write, act and produce a variety of satirical television programs, including the infamous "Talking to Americans" (2001) and "Christmas in Kabul" (2003). Mercer also wrote, produced and starred in the Canadian sitcom "Made in Canada" from 1998 to its finale in 2002 and is the host of the History Channel's successful program "Seems Like Yesterday". After a brief absence from television, Mercer returned in 2003 with "Monday Report" a weekly political satire program on the CBC. Mercer, only in his 30s, has a fame in Canadian television that very few have achieved.

Although Mercer has not been given a 'star' on Canada's Walk of Fame or been inducted into the Order of Canada, his accomplishments in Canadian television are recognized and respected by his peers. Mercer has received over 20 Gemini Awards and a number of other industry awards. These include such prestigious awards like the Sir Peter Ustinov Award at the 2003 Banff Television Festival. Previous recipients include John Cleese, John Candy and Martin Short. Mercer is also the sole civilian recipient of the Canadian Armed Forces Commander Land Force Command commendation. He has also received 5 Canadian Comedy Awards, the Newfoundland and Labrador Art's Council's Artist of the Year Award and an Atlantic Journalism Award.

\section{Research Summary}

Rick Mercer was included in 407 articles in the four selected print media from 19982003. The following is a breakdown of those articles. 
Table 3.2

Summary of print media articles - Rick Mercer

\begin{tabular}{|l|l|l|l|l|l|}
\hline \multicolumn{1}{|c|}{ Rick Mercer } & $\begin{array}{c}\text { Halifax } \\
\text { Chronicle-Herald }\end{array}$ & $\begin{array}{c}\text { Toronto } \\
\text { Star }\end{array}$ & $\begin{array}{c}\text { Vancouver } \\
\text { Sun }\end{array}$ & $\begin{array}{c}\text { Maclean's } \\
\text { Magazine }\end{array}$ & TOTAL \\
\hline Total \# Articles & 131 & 189 & 84 & 3 & 407 \\
\hline & & & & & \\
\hline Headline & 17 & 6 & 11 & 1 & 35 \\
\hline Lead Line & 22 & 20 & 14 & 3 & 59 \\
\hline Illustrations & 35 & 32 & 14 & 0 & 81 \\
\hline & & & & & \\
\hline Content: & & & & & \\
\hline Industry & 46 & 106 & 27 & 2 & 181 \\
\hline Awards & 51 & 30 & 16 & 0 & 97 \\
\hline Personal Profiles & 5 & 2 & 2 & 1 & 10 \\
\hline Events & 5 & 7 & 0 & 0 & 12 \\
\hline Politics & 9 & 23 & 11 & 0 & 43 \\
\hline General Interest & 15 & 21 & 28 & 0 & 64 \\
\hline & & & & & \\
\hline Name Dropping & 105 & 181 & 60 & 0 & 346 \\
\hline
\end{tabular}

Rick Mercer was the celebrity with the most coverage in the study. What is most interesting is the variance in his coverage in Eastern and Central Canada and in the West. Also, the extent of name dropping is significant, representing $85 \%$ of his exposure.

\section{$\underline{\text { Sarah Polley }}$}

Born in Toronto, Ontario on January $8^{\text {th }}, 1979$, Sarah Polley is part of a "showbiz" family; both her parents and one of her brothers are actors and her other brother is a casting director and producer. A mere 25, Polley has appeared in over 40 productions and is considered a veteran actor in Canadian television. Her first appearance was in Disney's 1985 film One Magic Christmas. However, Polley is best known for her role as Sarah Stanley in CBC's "Road to Avonlea" (1989-1996).

Since "Road to Avonlea" Polley has found continued success in Canadian film and television. Polley has received 8 Gemini Nominations and 2 Gemini Awards, 5 
Genie nominations resulting in 2 Genie awards and a Canadian Comedy Award (2000), has been nominated for a GOYA Award (2003), and has won a Boston Society of Film Critics Award (1997). She was nominated for an Independent Spirit Award (2000), awarded a National Board of Review Award (1997), won a Vancouver's Film Critic Circle Award (2004) and has been nominated three times for a Young Artists Award. Polley works predominantly in Canada. She had signed on to star in Cameron Crowe's Almost Famous (2000), however she dropped out of the film to work with the acclaimed and Genie winning director John Greyson (Hopwood, 2004: para6). Polley has continually worked with Canada's top directors, such as Atom Egoyan, Clement Virgo, Don McKellar, Thom Fitzgerald, Kevin Sullivan, Patricia Rozema and David Cronenberg. Apart from acting, Sarah Polley is known for her political activism in Ontario and Canada.

\section{Research Summary}

Sarah Polley was included in a total of 356 articles from 1998-2003 in the selected print media. The following is a breakdown of those articles. 
Table 3.3

Summary of print media articles - Sarah Polley

\begin{tabular}{|l|l|l|l|l|l|}
\hline \multicolumn{1}{|c|}{ Sarah Polley } & $\begin{array}{c}\text { Halifax } \\
\text { Chronicle-Herald }\end{array}$ & $\begin{array}{c}\text { Toronto } \\
\text { Star }\end{array}$ & $\begin{array}{c}\text { Vancouver } \\
\text { Sun }\end{array}$ & $\begin{array}{c}\text { Maclean's } \\
\text { Magazine }\end{array}$ & TOTAL \\
\hline Total \# Articles & 59 & 190 & 101 & 6 & 356 \\
\hline & & 5 & 2 & 0 & 8 \\
\hline Headline & 1 & 24 & 14 & 5 & 47 \\
\hline Lead Line & 4 & 26 & 16 & 3 & 47 \\
\hline Illustrations & 2 & & & & \\
\hline & & & & & \\
\hline Content: & & 127 & 69 & 3 & 254 \\
\hline Industry & 55 & 10 & 10 & 0 & 22 \\
\hline Awards & 2 & 8 & 0 & 3 & 12 \\
\hline Personal Profiles & 1 & 10 & 11 & 0 & 21 \\
\hline Events & 0 & 11 & 5 & 0 & 17 \\
\hline Politics & 1 & 24 & 6 & 0 & 30 \\
\hline General Interest & 0 & & & & \\
\hline & & 166 & 78 & 2 & 301 \\
\hline Name Dropping & 55 & & & & \\
\hline
\end{tabular}

Of the 356 articles, $84.6 \%$ fell into the name dropping category. Again it is interesting to note the regional variance in Polley's media coverage. Polley also received few headlines or articles that were personal profiles.

\section{$\underline{\text { Paul Gross }}$}

Born in Calgary, Alberta on April $30^{\text {th }} 1959$, Paul Gross is best known for his role as the Canadian Mountie in "Due South" (1994-1998). Paul Gross began his acting career in his early teens in Washington on the stage and eventually in television commercials.$^{3}$ He attended the University of Alberta, where he earned a degree in drama. Gross began making a name for himself with his performances at the Stratford

\footnotetext{
${ }^{3}$ His father, Bob Gross was a Tank Commander in the Canadian Army and a result Gross spent many years travelling around from base to base.
} 
Festival in Ontario. During his years at the Stratford Festival, Gross was credited as being the next big thing in Canadian stage acting.

In the late 1980s Gross made the jump to television and appeared in numerous television and film productions, including the Canadian cult classic "The Red Green Show" (1991). However, it was in 1994 when Gross, or at least his character, became a household name. Gross portrayed Constable Benton Fraser in the Canadian-American co-production "Due South". His image has set young ladies hearts afire.

Since the demise of the television series in 1998, Gross has continued to work in Canadian film and television. In 2002, he was part of Canadian film history with the release of Men with Brooms (actor, writer and director). This was the first Canadian film to have a same day national film release. It also had a marketing budget of one million dollars - an exorbitant sum in the Canadian film industry. Over his career he has been nominated for a Genie Award, 13 Gemini Awards, 2 Dora Awards, and has received 4 Gemini Awards, 1 Dora Award, 2 Alberta Playwright Awards and a Clifford E. Lee National Playwriting Award. He also received the Annual Heart of the Nation Award in 1999. Most recently, Gross has become an activist for Canadian drama, taking his message right to Parliament Hill.

\section{Research Summary}

Paul Gross was included in 300 articles in the four selected print media from 1998-2003. The following is a breakdown of those articles. 
Table 3.4

Summary of print media articles - Paul Gross

\begin{tabular}{|l|l|l|l|l|l|}
\hline \multicolumn{1}{|c|}{ Paul Gross } & $\begin{array}{c}\text { Halifax } \\
\text { Chronicle-Herald }\end{array}$ & $\begin{array}{c}\text { Toronto } \\
\text { Star }\end{array}$ & $\begin{array}{c}\text { Vancouver } \\
\text { Sun }\end{array}$ & $\begin{array}{c}\text { Maclean's } \\
\text { Magazine }\end{array}$ & TOTAL \\
\hline Total \# Articles & 48 & 203 & 42 & 7 & 300 \\
\hline & & & & & \\
\hline Headline & 12 & 20 & 19 & 7 & 23 \\
\hline Lead Line & 12 & 20 & 19 & 7 & 58 \\
\hline Illustrations & 19 & 22 & 11 & 4 & 46 \\
\hline & & & & & \\
\hline Content: & & & & & \\
\hline Industry & 33 & 131 & 27 & 5 & 196 \\
\hline Awards & 7 & 14 & 3 & 0 & 24 \\
\hline Personal Profiles & 3 & 17 & 5 & 2 & 27 \\
\hline Events & 1 & 16 & 0 & 0 & 17 \\
\hline Politics & 3 & 11 & 2 & 0 & 16 \\
\hline General Interest & 1 & 14 & 5 & 0 & 20 \\
\hline & & & & & \\
\hline Name Dropping & 35 & 154 & 37 & 0 & 227 \\
\hline
\end{tabular}

The regional variance for Paul Gross is striking, almost a 75\% decrease in coverage in Atlantic and Western Canada. Of the 300 articles $75.7 \%$ fell into the name dropping category. It is also interesting to note that, despite the regional variance, his coverage in headlines, leadlines and illustrations is stable.

\section{Cathy Jones}

Born Catherine Frederica Theresa Jones on April 6, 1955 in St. John's Newfoundland, Cathy Jones is a veteran of Canadian television programming. Jones' acting career can be traced back to 1973 at the Newfoundland Traveling Theatre Company (Memorial University of Newfoundland, 2000), where she performed in the predecessor to "CODCO" (1986), "Cod on a Stick". In the 1980s Jones continued her stage acting with the Sheila's Brush Company and The Resource Centre for the Arts. 
Her Canadian television career began with the show "The Wonderful Grand Band"; however, it was her performance in "CODCO" that really propelled her career forward. Most recently Jones has been part of the long running CBC series "This Hour has 22 Minutes". Although her acting credits are few, her talent is abundant. Jones is the recipient of 24 Gemini Nominations and 16 Gemini Awards, 8 Canadian Comedy Awards nominations and 5 Canadian Comedy Awards, and 3 Writers Guild of Canada Awards. She has also received an honorary doctorate from Memorial University of Newfoundland.

\section{Research Summary}

Cathy Jones was included in 177 articles in the four selected print media from 1998-2003.

The following is a breakdown of those articles.

Table 3.5

Summary of print media articles - Cathy Jones

\begin{tabular}{|l|l|l|l|l|l|}
\hline \multicolumn{1}{|c|}{ Cathy Jones } & $\begin{array}{c}\text { Halifax } \\
\text { Chronicle-Herald }\end{array}$ & $\begin{array}{c}\text { Toronto } \\
\text { Star }\end{array}$ & $\begin{array}{c}\text { Vancouver } \\
\text { Sun }\end{array}$ & $\begin{array}{l}\text { Maclean's } \\
\text { Magazine }\end{array}$ & TOTAL \\
\hline Total \# Articles & 81 & 67 & 27 & 2 & 177 \\
\hline & & & & & \\
\hline Headline & 3 & 3 & 1 & 0 & 7 \\
\hline Lead Line & 8 & 1 & 1 & 2 & 12 \\
\hline Illustrations & 18 & 7 & 6 & 0 & 31 \\
\hline & & & & & \\
\hline Content: & & & & & \\
\hline Industry & 29 & 26 & 17 & 1 & 73 \\
\hline Awards & 23 & 19 & 6 & 1 & 49 \\
\hline Personal Profiles & 0 & 2 & 1 & 0 & 3 \\
\hline Events & 20 & 13 & 1 & 0 & 34 \\
\hline Politics & 6 & 0 & 0 & 0 & 6 \\
\hline General Interest & 3 & 7 & 2 & 0 & 12 \\
\hline & & & & & \\
\hline Name Dropping & 65 & 61 & 25 & 2 & 153 \\
\hline
\end{tabular}

Cathy Jones received a lower amount of print media coverage than the other 6 celebrities. She likewise received fewer headlines, illustrations and personal profiles. It is also 
interesting that $86.4 \%$ of the articles with references to Jones fell into the name dropping category.

\section{Mary Walsh}

Born May $13^{\text {th }}, 1952$ in St. John's Newfoundland, Mary Walsh is best known for her role as 'Princess Warrior' in "This Hour has 22 Minutes." Walsh began her acting career alongside Cathy Jones in the Newfoundland Traveling Theatre Company in the early 1970s. While touring in Toronto Walsh was part of the performance which led to the production of "CODCO". "CODCO" helped to propel Walsh's career and landed her a role in "This Hour Has 22 Minutes". Walsh has been involved in numerous projects since her days at the Newfoundland Traveling Theatre Co. Most recently she hosts a series, "Mary Walsh: Open Book", which allows her to explore her love of the written word.

Walsh has received numerous awards. In 2000 she was inducted into the Order of Canada. Walsh has been nominated for 25 Gemini Awards (and has received 16 Gemini Awards), 5 Canadian Comedy Awards (receiving 3), was nominated for one Genie Award in 2001, won a Atlantic Film Festival Award and has been nominated for 3 Writer's Guild of Canada Awards (all of which she won).

\section{Research Summary}

Mary Walsh was included in 340 articles in the four selected print media from 19982003. The following is a breakdown of those articles. 
Table 3.6

Summary of print media articles - Mary Walsh

\begin{tabular}{|l|l|l|l|l|l|}
\hline \multicolumn{1}{|c|}{ Mary Walsh } & $\begin{array}{c}\text { Halifax } \\
\text { Chronicle-Herald }\end{array}$ & $\begin{array}{c}\text { Toronto } \\
\text { Star }\end{array}$ & $\begin{array}{c}\text { Vancouver } \\
\text { Sun }\end{array}$ & $\begin{array}{l}\text { Maclean's } \\
\text { Magazine }\end{array}$ & TOTAL \\
\hline Total \# Articles & 99 & 152 & 83 & 6 & 340 \\
\hline & & & & & \\
\hline Headline & 14 & 10 & 8 & 1 & 33 \\
\hline Lead line & 20 & 11 & 0 & 2 & 36 \\
\hline Illustrations & 17 & 26 & 5 & 3 & 51 \\
\hline & & & & & \\
\hline Content: & & & & & \\
\hline Industry & 49 & 69 & 45 & 2 & 165 \\
\hline Awards & 19 & 26 & 14 & 0 & 59 \\
\hline Personal Profiles & 6 & 3 & 6 & 4 & 19 \\
\hline Events & 6 & 18 & 7 & 0 & 31 \\
\hline Politics & 7 & 15 & 1 & 0 & 23 \\
\hline General Interest & 12 & 21 & 10 & 0 & 43 \\
\hline & & & & & \\
\hline Name Dropping & 70 & 141 & 66 & 1 & 278 \\
\hline
\end{tabular}

Walsh received the most exposure in the Toronto Star, with 152 articles. Although her exposure was less in Atlantic and Western Canada (99 and 83 respectively), it was stable, suggesting only a small regional variance. It is interesting to note that only 11 of the Toronto Star articles were specifically on Mary Walsh, whereas 141 articles fell into the name-dropping category. Overall, $81.8 \%$ of the articles were of the name dropping type.

\section{Nicholas Campbell}

Born March $24^{\text {th }} 1952$ in Toronto, Ontario, Nicholas Campbell has a long and distinguished career in Canadian television and film. Campbell attended Queen's University, studying English and Drama, before heading to England to study at the Royal Academy of Dramatic Arts (RADA) (TV Tome, 2004). His first role in film was in The Omen (1976), however, he has largely remained in Canada for his acting career. Most 
recently Campbell plays Dominic Da Vinci in CBC's critically acclaimed drama 'Da Vinci’s Inquest."

Besides acting, Campbell is a credited director and writer. Campbell's work in Canadian television and film has garnered him 3 Genie nominations, a Director's Guild of Canada Award nomination and 7 Gemini nominations. He has received 3 Gemini Awards.

\section{Research Summary}

Nicholas Campbell was included in 237 articles in the four selected print media from 1998-2003. The following is a breakdown of those articles.

Table 3.7

Summary of print media articles - Nicholas Campbell

\begin{tabular}{|l|l|l|l|l|l|}
\hline Nicholas Campbell & $\begin{array}{c}\text { Halifax } \\
\text { Chronicle-Herald }\end{array}$ & $\begin{array}{c}\text { Toronto } \\
\text { Star }\end{array}$ & $\begin{array}{c}\text { Vancouver } \\
\text { Sun }\end{array}$ & $\begin{array}{c}\text { Maclean's } \\
\text { Magazine }\end{array}$ & TOTAL \\
\hline Total \# Articles & 33 & 94 & 107 & 3 & 237 \\
\hline & & & & & \\
\hline Headline & 5 & 4 & 6 & 1 & 16 \\
\hline Lead Line & 4 & 5 & 7 & 3 & 19 \\
\hline Illustrations & 4 & 13 & 31 & 1 & 49 \\
\hline & & & & & \\
\hline Content: & & & & & \\
\hline Industry & 17 & 57 & 48 & 1 & 123 \\
\hline Awards & 12 & 28 & 30 & 0 & 70 \\
\hline Personal Profiles & 1 & 1 & 5 & 2 & 9 \\
\hline Events & 2 & 5 & 6 & 0 & 13 \\
\hline Politics & 0 & 2 & 5 & 0 & 7 \\
\hline General Interest & 1 & 1 & 13 & 0 & 15 \\
\hline & & & & & \\
\hline Name Dropping & 30 & 97 & 84 & 0 & 211 \\
\hline
\end{tabular}

Again, there is an obvious regional bias. Campbell works primarily out of Vancouver, where he received the majority of his coverage, and in Eastern Canada he received the least. Also, $89 \%$ of the articles on him fell into the name dropping category. 


\section{$\underline{\text { Sonja Smits }}$}

Born on September $8^{\text {th }}, 1958$ in the Ottawa Valley, Ontario, Smits is a highly respected veteran Canadian actor. She has continuously worked in Canadian television drama beginning with "Street Legal" (1987 - 1994), “Traders" (1996 - 2000) and currently "The Eleventh Hour" (2002).

Smits has been nominated for 2 Genie Awards and 5 Gemini Awards, winning the Gemini Award in 1988 for her role in critically acclaimed drama "Street Legal". In 2004 Smits received the ACTRA Toronto Award of Excellence.

\section{Research Summary}

Sonja Smits was included in 149 articles in the four selected print media from 1998-2003.

The following is a breakdown of those articles.

Table 3.8

Summary of print media articles - Sonja Smits

\begin{tabular}{|l|l|l|l|l|l|}
\hline \multicolumn{1}{|c|}{ Sonja Smits } & $\begin{array}{c}\text { Halifax } \\
\text { Chronicle-Herald }\end{array}$ & $\begin{array}{c}\text { Toronto } \\
\text { Star }\end{array}$ & $\begin{array}{c}\text { Vancouver } \\
\text { Sun }\end{array}$ & $\begin{array}{c}\text { Maclean's } \\
\text { Magazine }\end{array}$ & TOTAL \\
\hline Total \# Articles & 18 & 119 & 10 & 2 & 149 \\
\hline & & & & & \\
\hline Headline & 1 & 2 & 1 & 1 & 5 \\
\hline Lead Line & 1 & 8 & 1 & 2 & 12 \\
\hline Illustrations & 4 & 28 & 3 & 1 & 36 \\
\hline & & & & & \\
\hline Content: & & & & & \\
\hline Industry & 11 & 55 & 7 & 1 & 74 \\
\hline Awards & 2 & 14 & 3 & 0 & 19 \\
\hline Personal Profiles & 0 & 4 & 0 & 1 & 5 \\
\hline Events & 0 & 15 & 0 & 0 & 15 \\
\hline Politics & 2 & 10 & 0 & 0 & 12 \\
\hline General Interest & 3 & 21 & 0 & 0 & 24 \\
\hline & & & & & \\
\hline Name Dropping & 17 & 110 & 10 & 1 & 138 \\
\hline
\end{tabular}


Again the regional variance is striking, as is the below average findings for headline, illustration and leadline, combined with higher numbers for name dropping. In fact, $99 \%$ of the total articles including Smits fell into the name dropping category.

\section{Research Highlights for the sampled Celebrities}

The following section summarizes and compares the data on the sampled celebrities by category.

\section{Total Number of Articles}

As the table below illustrates, Rick Mercer appeared in more articles than any other of the sampled celebrities. He appeared most frequently in the Halifax ChronicleHerald and the Toronto Star. Sarah Polley, Mary Walsh and Paul Gross followed, each receiving 300 or more of the sampled articles. Appearing almost half as often as Mercer were Nicholas Campbell and Cathy Jones. Sonja Smits finishes off this list with the fewest articles at 149, one third the number that Mercer received. It is also interesting to note that of the top three celebrities, Mercer and Walsh are known more for their work in political satire; whereas in the bottom we find strictly dramatic actors (Campbell and Smits). 
Table 3.9

\begin{tabular}{|l|l|l|l|l|l|}
\hline & $\begin{array}{c}\text { Halifax Chronicle- } \\
\text { Herald }\end{array}$ & $\begin{array}{c}\text { Toronto } \\
\text { Star }\end{array}$ & $\begin{array}{c}\text { Vancouver } \\
\text { Sun }\end{array}$ & $\begin{array}{l}\text { Maclean's } \\
\text { Magazine }\end{array}$ & TOTAL \\
\hline Rick Mercer & 131 & 189 & 84 & 3 & 407 \\
\hline Sarah Polley & 59 & 190 & 101 & 6 & 356 \\
\hline Mary Walsh & 99 & 152 & 83 & 6 & 340 \\
\hline Paul Gross & 48 & 203 & 42 & 7 & 300 \\
\hline Nicholas Campbell & 33 & 94 & 107 & 3 & 237 \\
\hline Cathy Jones & 81 & 67 & 27 & 2 & 177 \\
\hline Sonja Smits & 18 & 119 & 10 & 2 & 149 \\
\hline
\end{tabular}

$\underline{\text { Headlines }}$

Rick Mercer again is at the top of the list, with his name appearing in 35 (21.6 percent) of the 162 sampled articles that included the name of celebrity within the headline. However, Mary Walsh received 33 of the headlines, only 2 less than Mercer. Paul Gross and Nicholas Campbell also did well in this category, receiving 10 percent or more of potential headlines (Nicholas Campbell was slightly under at 9.8 percent). Sarah Polley, Sonja Smits and Cathy Jones were not discovered in the headlines as often, each receiving fewer than 5 percent of the potential headlines.

Table 3.10

\begin{tabular}{|l|l|l|l|l|l|}
\hline & $\begin{array}{c}\text { Halifax Chronicle- } \\
\text { Herald }\end{array}$ & $\begin{array}{c}\text { Toronto } \\
\text { Star }\end{array}$ & $\begin{array}{c}\text { Vancouver } \\
\text { Sun }\end{array}$ & $\begin{array}{c}\text { Maclean's } \\
\text { Magazine }\end{array}$ & TOTAL \\
\hline Total: Headline & 53 & 50 & 48 & 11 & 162 \\
\hline & & & & & \\
\hline Rick Mercer & 17 & 6 & 11 & 1 & 35 \\
\hline Mary Walsh & 14 & 10 & 8 & 1 & 33 \\
\hline Paul Gross & 12 & 20 & 19 & 7 & 23 \\
\hline Nicholas Campbell & 5 & 4 & 6 & 1 & 16 \\
\hline Sarah Polley & 1 & 5 & 2 & 0 & 8 \\
\hline Cathy Jones & 3 & 3 & 1 & 0 & 7 \\
\hline Sonja Smits & 1 & 2 & 1 & 1 & 5 \\
\hline
\end{tabular}


$\underline{\text { Lead Lines }}$

In this category Mercer again led. He appeared in the most lead lines of the sampled celebrities with 59 articles. Paul Gross was not far behind with 58 articles. Sarah Polley and Mary Walsh follow with 47 and 36 articles in which their name appeared in the lead line of the article. However, it should be noted that Sarah Polley received the most lead lines in the Toronto Star and Paul Gross in the Vancouver Sun. Nicholas Campbell, Cathy Jones and Sonja Smits were the least three celebrities to be found within the lead line.

Table 3.11

\begin{tabular}{|l|l|l|l|l|l|}
\hline & $\begin{array}{c}\text { Halifax Chronicle- } \\
\text { Herald }\end{array}$ & $\begin{array}{c}\text { Toronto } \\
\text { Star }\end{array}$ & $\begin{array}{c}\text { Vancouver } \\
\text { Sun }\end{array}$ & $\begin{array}{c}\text { Maclean's } \\
\text { Magazine }\end{array}$ & TOTAL \\
\hline Total: Lead Line & 71 & 89 & 56 & 24 & 240 \\
\hline & & & & & \\
\hline Rick Mercer & 22 & 20 & 14 & 3 & 59 \\
\hline Paul Gross & 12 & 20 & 19 & 7 & 58 \\
\hline Sarah Polley & 4 & 24 & 14 & 5 & 47 \\
\hline Mary Walsh & 20 & 11 & 0 & 2 & 36 \\
\hline Nicholas Campbell & 4 & 5 & 7 & 3 & 19 \\
\hline Cathy Jones & 8 & 1 & 1 & 2 & 12 \\
\hline Sonja Smits & 1 & 8 & 1 & 2 & 12 \\
\hline
\end{tabular}

\section{Illustrations}

Mercer, was the most visually represented celebrity in the sampled articles. Mercer's image was included in 81 (23.1 percent) of the potential 351 illustrations in sample. Mary Walsh, Nicholas Campbell, Sarah Polley and Paul Gross, all received between 13-14 percent of the illustrations, whereas Sonja Smits and Cathy Jones 
appeared in 10 percent or less of the potential illustrations. It should also be noted that Nicholas Campbell appeared in the most illustrations in the Vancouver Sun.

Table 3.12

\begin{tabular}{|l|l|l|l|l|l|}
\hline & $\begin{array}{c}\text { Halifax Chronicle- } \\
\text { Herald }\end{array}$ & $\begin{array}{c}\text { Toronto } \\
\text { Star }\end{array}$ & $\begin{array}{c}\text { Vancouver } \\
\text { Sun }\end{array}$ & $\begin{array}{c}\text { Maclean's } \\
\text { Magazine }\end{array}$ & TOTAL \\
\hline Total: Illustrations & 99 & 154 & 86 & 12 & 351 \\
\hline & & & & & \\
\hline Rick Mercer & 35 & 32 & 14 & 0 & 81 \\
\hline Mary Walsh & 17 & 26 & 5 & 3 & 51 \\
\hline Nicholas Campbell & 4 & 13 & 31 & 1 & 49 \\
\hline Sarah Polley & 2 & 26 & 16 & 3 & 47 \\
\hline Paul Gross & 19 & 22 & 11 & 4 & 46 \\
\hline Sonja Smits & 4 & 28 & 3 & 1 & 36 \\
\hline Cathy Jones & 18 & 7 & 6 & 0 & 31 \\
\hline
\end{tabular}

\section{Content}

Without exception the most common content for each celebrity within the sampled articles was related to the industry of television and film. Awards, events and general interest content followed industry. Other significant findings include the low results of personal profiles and award shows for some of the celebrities. These categories did not register in the Halifax Chronicle-Herald or the Vancouver Sun for Sonja Smits. 
Table 3.13

\begin{tabular}{|c|c|c|c|c|c|c|c|c|c|c|c|c|c|c|c|c|c|c|c|c|c|c|c|c|c|c|c|c|c|c|}
\hline & \multicolumn{6}{|c|}{ Halifax Chronicle-Herald } & \multicolumn{6}{|c|}{ Toronto Star } & \multicolumn{6}{|c|}{ Vancouver Sun } & \multicolumn{6}{|c|}{ Maclean's Magazine } & \multicolumn{6}{|c|}{ TOTAL } \\
\hline & $\underline{I}$ & $\underline{\mathrm{A}}$ & $\underline{\mathbf{P}}$ & $\underline{E}$ & $\underline{\text { Po }}$ & $\underline{\mathbf{G}}$ & $\underline{I}$ & $\underline{\mathrm{A}}$ & $\underline{\mathbf{P}}$ & $\underline{E}$ & $\underline{\text { Po }}$ & $\underline{\mathrm{G}}$ & $\underline{I}$ & $\underline{\mathrm{A}}$ & $\underline{\mathrm{P}}$ & $\underline{\mathrm{E}}$ & $\mathrm{PO}$ & $\underline{\mathrm{G}}$ & $\underline{I}$ & $\underline{\mathrm{A}}$ & $\underline{\mathrm{P}}$ & $\underline{E}$ & $\mathrm{PO}$ & $\underline{\mathrm{G}}$ & $\underline{\mathrm{I}}$ & $\underline{\mathrm{A}}$ & $\underline{P}$ & $\underline{E}$ & $\underline{\mathrm{PO}}$ & $\underline{\mathrm{G}}$ \\
\hline Total & 240 & 116 & 16 & 34 & 28 & 35 & 571 & 141 & 37 & 84 & 72 & 109 & 241 & 83 & 19 & 25 & 24 & 64 & 14 & 0 & 13 & 0 & 0 & 0 & 1066 & 340 & 85 & 143 & 124 & 208 \\
\hline R.M. & 46 & 51 & 5 & 5 & 9 & 15 & 106 & 30 & 2 & 7 & 23 & 21 & 27 & 16 & 2 & 0 & 11 & 28 & 2 & 0 & 1 & 0 & 0 & 0 & 181 & 97 & 10 & 12 & 43 & 64 \\
\hline S.P. & 55 & 2 & 1 & 0 & 1 & 0 & 127 & 10 & 8 & 10 & 11 & 24 & 69 & 10 & 0 & 11 & 5 & 6 & 3 & 0 & 3 & 0 & 0 & 0 & 254 & 22 & 12 & 21 & 17 & 30 \\
\hline P.G. & 33 & 7 & 3 & 1 & 3 & 1 & 131 & 14 & 17 & 16 & 11 & 14 & 27 & 3 & 5 & 0 & 2 & 5 & 5 & 0 & 2 & 0 & 0 & 0 & 196 & 24 & 27 & 17 & 16 & 20 \\
\hline C.J. & 29 & 23 & 0 & 20 & 6 & 3 & 26 & 19 & 2 & 13 & 0 & 7 & 17 & 6 & 1 & 1 & 0 & 2 & 1 & 1 & 0 & 0 & 0 & 0 & 73 & 49 & 3 & 34 & 6 & 12 \\
\hline M.W. & 49 & 19 & 6 & 6 & 7 & 12 & 69 & 26 & 3 & 18 & 15 & 21 & 45 & 14 & 6 & 7 & 1 & 10 & 2 & 0 & 4 & 0 & 0 & 0 & 165 & 59 & 19 & 31 & 23 & 43 \\
\hline N.C. & 17 & 12 & 1 & 2 & 0 & 1 & 57 & 28 & 1 & 5 & 2 & 1 & 48 & 30 & 5 & 6 & 5 & 13 & 1 & 0 & 2 & 0 & 0 & 0 & 123 & 70 & 9 & 13 & 7 & 15 \\
\hline S.S. & 11 & 2 & 0 & 0 & 2 & 3 & 55 & 14 & 4 & 15 & 10 & 21 & 7 & 3 & 0 & 0 & 0 & 0 & 1 & 0 & 1 & 0 & 0 & 0 & 74 & 19 & 5 & 15 & 12 & 24 \\
\hline
\end{tabular}

\section{LEGEND}

\begin{tabular}{|l|} 
I - industry \\
A - awards \\
P-profiles \\
E- events \\
Po-politics \\
G-general interest
\end{tabular}

\begin{tabular}{|l|}
\hline R.M. - Rick Mercer \\
S.P. - Sarah Polley \\
P.G. - Paul Gross \\
C.J. - Cathy Jones \\
M.W. - Mary Walsh \\
N.C. - Nicholas Campbell \\
S.S. - Sonja Smits
\end{tabular}




\section{Name Dropping}

Once again Mercer dominates this category with 346 name drops in the sampled articles. Sarah Polley, Mary Walsh, Paul Gross and Nicholas Campbell were referenced between 200 and 300 times in the sampled articles. Cathy Jones and Sonja Smits received the lowest number of references, between $100-200$ references. For each celebrity the Toronto Star ranked the highest for name references. However, when the percentage of name dropping is calculated for each celebrity there are interesting results. $99 \%$ of the articles that included Sonja Smits were name drops. So, although she ranked the lowest, the number of references in the Toronto Star was comparatively high.

Table 3.14

\begin{tabular}{|l|l|l|l|l|l|}
\hline & $\begin{array}{c}\text { Halifax Chronicle- } \\
\text { Herald }\end{array}$ & $\begin{array}{c}\text { Toronto } \\
\text { Star }\end{array}$ & $\begin{array}{c}\text { Vancouver } \\
\text { Sun }\end{array}$ & $\begin{array}{c}\text { Maclean's } \\
\text { Magazine }\end{array}$ & TOTAL \\
\hline $\begin{array}{c}\text { Total: Name } \\
\text { Dropping }\end{array}$ & 377 & 910 & 360 & 6 & 1653 \\
\hline & & & & & \\
\hline Rick Mercer & 105 & 181 & 60 & 0 & 346 \\
\hline Sarah Polley & 55 & 166 & 78 & 2 & 301 \\
\hline Mary Walsh & 70 & 141 & 66 & 1 & 278 \\
\hline Paul Gross & 35 & 154 & 37 & 0 & 227 \\
\hline Nicholas Campbell & 30 & 97 & 84 & 0 & 211 \\
\hline Cathy Jones & 65 & 61 & 25 & 2 & 153 \\
\hline Sonja Smits & 17 & 110 & 10 & 1 & 138 \\
\hline
\end{tabular}

The category of name dropping is complex as it has advantages and disadvantages in relation to the visibility complex. This complexity will be elaborated on in Chapter Four.

In conclusion, this chapter highlights the variances in the coverage of English Canadian celebrities. The most striking variance can be seen in the regional bias. The amount of articles, 1966 over a six year period, seems like a lot of coverage, but this impression must be subjected to closer scrutiny. For example, the data suggests that with 
the high amount of name dropping and low number of celebrity profiles, the type of celebrity coverage found in these sources is ill suited to cultivating celebrity. The next chapter will further analyze the data as it relates to the visibility complex discussed in Chapter Two and further discuss whether Canadian news media in print help to cultivate an English Canadian celebrity culture. 


\title{
CHAPTER 4:
}

\section{THE STATE OF ENGLISH-CANADIAN CELEBRITY CULTURE: ANALYSIS AND CONCLUSIONS}

\author{
“... high visibility is axiomatic: entertainers earn their \\ living by attracting attention. The better known they are, \\ the larger their audience, and the larger their premium. \\ It's not surprising that entertainers were among the earliest \\ users of the machinery of visibility seeking. Needing to \\ constantly manage their image with audiences, entertainers \\ depend heavily on publicists, agents, managers, and \\ coaches" (Rein, 2003: 87).
}

The previous chapter presented the research findings from a survey of six years of news coverage of seven Canadian celebrities from selected print media. The purpose of this chapter is to analyze the data to see what they reveal about the English-Canadian star system. As Chapter Two concluded, the key element of celebrity is visibility, which has numerous components: celebrity reach, ease of access, illusion of intimacy and newsworthy-ness. The relative strength of these components in Canadian media coverage of homegrown stars can be deduced from the research results presented in Chapter Three. Using the visibility complex as a lens to analyze the data three conclusions can be drawn:

- A regional bias exists which suggests that celebrity is not transcending to the national level;

- There is an insufficient amount of celebrity coverage in print media; and 
- There is an insufficient quantity of the type of celebrity coverage which would lead to intimacy, ease of access and newsworthiness.

\section{Celebrity Reach}

In the Visibility Reach Pyramid, Rein (2003), suggests that there are 5 levels: invisible, local, regional, national and international (93-94). To sustain celebrity, one must conquer space, which means transcending the local and regional levels to reach the national and international (however, in this study the concern is less international reach then it is national reach). If a celebrity fails to achieve this reach, their celebrity cannot be maintained.

The primary research indicates there is a spatial bias at work. The following table illustrates the total number of articles for each celebrity broken down by regional source.

Table 4.1

\begin{tabular}{|l|l|l|l|l|l|}
\hline \multicolumn{1}{|c|}{ Celebrity } & $\begin{array}{c}\text { Halifax Chronicle- } \\
\text { Herald }\end{array}$ & $\begin{array}{c}\text { Toronto } \\
\text { Star }\end{array}$ & $\begin{array}{l}\text { Vancouver } \\
\text { Sun }\end{array}$ & $\begin{array}{l}\text { Maclean's } \\
\text { Magazine }\end{array}$ & TOTAL \\
\hline Rick Mercer & 131 & 189 & 84 & 3 & 407 \\
\hline Sarah Polley & 59 & 190 & 101 & 6 & 356 \\
\hline Paul Gross & 48 & 203 & 42 & 7 & 300 \\
\hline Cathy Jones & 81 & 67 & 27 & 2 & 177 \\
\hline Mary Walsh & 99 & 152 & 83 & 6 & 340 \\
\hline Nicholas Campbell & 33 & 94 & 107 & 3 & 237 \\
\hline Sonja Smits & 18 & 119 & 10 & 2 & 149 \\
\hline
\end{tabular}

The shaded area indicates the primary area of residence of the celebrity. The results for Sarah Polley, Paul Gross, Cathy Jones, Nicholas Campbell and Sonja Smits all illustrate that there is a considerably larger number of articles in the print media located in a 
celebrity's home region. This finding suggests that there could be a regional bias to consider.

Although Rick Mercer and Mary Walsh are from the East Coast, their numbers were larger in the Toronto Star. During the past five years these celebrities have been predominantly working out of Toronto on various projects, which might explain their higher numbers in the Toronto Star. Also, Toronto is a centre of film and television production. However, it could also suggest that these particular celebrities have expanded their reach to a national status. For some of the celebrities, reach to outside markets is almost non-existent. For instance, whereas Sonja Smits was referenced in 11.7 percent of the sampled Toronto Star papers, this ratio was drastically smaller in the other

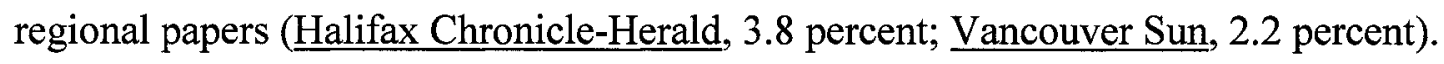
This geographical bias is also relevant to Paul Gross, who received 20 percent of the references in the Toronto Star samples, yet received only half of that amount in the

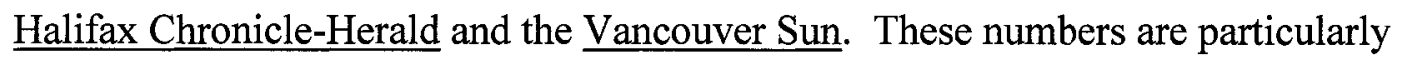
significant because all of these celebrities were on nationally broadcast shows. Moreover, celebrities Sonja Smits and Paul Gross are not region-specific in their television and film productions. For instance, Paul Gross began his career in the prairie provinces and continues to travel across Canada on numerous projects. These results suggest that Canadian celebrities have difficulties extending their reach beyond their regional borders.

For a successful star system to maintain itself, celebrities cannot remain regional in their reach. Admittedly, newspapers are inherently regional in nature. Still this is something that must be overcome for celebrity to be achieved. Although the exact reason 
as to why this regional bias exists is not known, it still has implications for cultivating an English-Canadian star system. Celebrities must transcend the regional if a national star system is desired.

\section{Ease of Access}

A major component to the visibility of a celebrity lies in the access that the audience has to a celebrity. Unfortunately, people do not seek out celebrities in the same way one might seek out a particular pair of jeans at the local Winners. For that reason, the audience needs 'quick and easy access' to a celebrity. In print media this means the information about a celebrity needs to visible enough to immediately grab the attention of the audience.

If a celebrity is accessible the audience is constantly reminded of the celebrity. If there is too little exposure and too little access to the celebrity, audiences are forced to seek out the celebrities. Rein (2003) suggests this avenue of approach is unlikely considering the availability of more widely distributed information about other celebrities (309). In English-Canada this is even more problematic, considering the number of American celebrities that are available to us. From the data collected in the print media study the accessibility of English-Canadian celebrities appears low. The categories which suggest how accessible the celebrities are include: headline, lead line, illustrations and name dropping. Each of these categories allow for certain conclusions to be made about a celebrities' accessibility. The following table illustrates the accessibility of the selected celebrities: 
Table 4.2

\begin{tabular}{|l|l|l|l|l|l|}
\hline Total 7 Subjects & $\begin{array}{c}\text { Halifax Chronicle- } \\
\text { Herald }\end{array}$ & $\begin{array}{c}\text { Toronto } \\
\text { Star }\end{array}$ & $\begin{array}{c}\text { Vancouver } \\
\text { Sun }\end{array}$ & $\begin{array}{c}\text { Maclean's } \\
\text { Magazine }\end{array}$ & TOTAL \\
\hline Total \# Articles & 469 & 1014 & 454 & 29 & 1966 \\
\hline & & & & & \\
\hline Name Dropping & 377 & 910 & 360 & 6 & 1653 \\
\hline & & & & & \\
\hline Headline & 53 & 50 & 48 & 11 & 162 \\
\hline Lead Line & 71 & 89 & 56 & 24 & 240 \\
\hline Illustrations & 99 & 154 & 86 & 12 & 351 \\
\hline
\end{tabular}

A total of 1966 articles seems impressive. It suggests that the average reader of a daily newspaper would encounter an article mentioning a celebrity every other day or so.' Yet a quick glance at the statistics shows that the vast majority of these mentions $(84 \%)$ fall into the name dropping category. The relationship between accessibility and namedropping is complex. Name-dropping is the most frequent occurrence of celebrity coverage. The stable flow of name-dropping is encouraging as it suggests that name recognition would ensue. However, name dropping alone cannot transmit the information that is needed to make the celebrity completely accessible. Finding the article in which the name was dropped would take a conscious daily effort of searching through the hundreds of news pages everyday. Name dropping is desirable in that it keeps the celebrity's name in the news and conveys a sense that the reader should recognize the name. But it does little to build celebrity. It trades off whatever celebrity the name already has. In the name dropping category the name of the celebrity usually appeared in brackets. There was no real consistency on where within the article the

\footnotetext{
${ }^{1}$ The formula to obtain this calculation is as follows: dividing the number of articles, by
} the number of days in the study $(2190 / 1966=.8$ days $)$ 
celebrity's name would appear. Quite often it would be in brackets after the name of a television or film production to indicate that they were involved in the cast.

When the name dropping articles are taken out, the total number of articles is much less impressive. If all of the name dropping articles were to be removed from the sample, only 313 articles would remain - an average of approximately 52 articles a year, or roughly 13 per publication. A reader who read the newspaper would be exposed to approximately one celebrity article per month. If that reader also subscribes to Maclean's, the frequency would increase to approximately 1.5 articles per month. Divide this number by seven (the number of celebrities under consideration) and it seems reasonable to conclude that these print media are doing little to secure memory lock for Canadian television stars.

This conclusion is reinforced when the type of coverage provided by the 313 nonname-dropping articles is scrutinized. Do these remaining articles provide ease of access and an illusion of intimacy? The following analysis of the articles' various components addresses this question.

The purpose of the headline is to grab the audience's attention. It helps the audience decide where to devote its reading time within the newspaper. In this study only 52 percent of the sampled articles included the name of the celebrity within the headline. This means that only 162 of 313 articles made the celebrity accessible to the audience.

Similarly the lead line of the story is used to grab the attention of the readers. However, as the data indicates celebrities are not overly accessible in this category either. Lead lines which included the name of a celebrity only occurred in 240 of the 313 
sampled articles. This means that 23 percent of the articles that were sampled would require the reader to read past the first line of the story to find information on a celebrity.

Illustrations are one of the more effective ways at making celebrities more accessible. As discussed in Chapter 2, the photograph has the ability to attract the notice of the reader more so than any other mechanism. Yet in all the sampled articles (1966) only 17.5 percent contained illustrations of the celebrity.

\section{Illusion of Intimacy}

Visibility not only depends on the access an audience has to the celebrity, it also depends on how the celebrity is seen. As previously noted in Chapter 2, the "illusion of intimacy' that the photograph and later the close-up in film and television provided go a long way to promote the celebrity amongst their audiences. The star system is reliant upon the connection between the celebrity and the audience. There is a desire to view the celebrity as more than just an actor or personality; the celebrity must also be seen as a real person.

The print media could play a significant role in making this connection between the celebrity and the audience. The category most closely associated with the creation of an 'illusion of intimacy' is the personal profile. The celebrity profile is considered one the most significant aspects of celebrity journalism. Profiling the celebrity makes them seem important and creates a connection between the celebrity and the audience. The following table indicates there are relatively few articles that are personal profiles: 
Table 4.3

\begin{tabular}{|l|l|l|l|l|l|}
\hline Total 7 Subjects & $\begin{array}{c}\text { Halifax Chronicle- } \\
\text { Herald }\end{array}$ & $\begin{array}{c}\text { Toronto } \\
\text { Star }\end{array}$ & $\begin{array}{c}\text { Vancouver } \\
\text { Sun }\end{array}$ & $\begin{array}{c}\text { Maclean's } \\
\text { Magazine }\end{array}$ & TOTAL \\
\hline Personal Profiles & 16 & 37 & 19 & 13 & 85 \\
\hline
\end{tabular}

The data collected from the print media study show that only 85 of the 1966 $(4.3 \%)$ sampled articles were a form of profiles. ${ }^{2}$ This is significant as it suggests the access that the average reader would have to celebrity profiles would be limited.

To demonstrate this point further, the following is a closer examination of the profiling and name dropping findings for Cathy Jones:

Table 4.4

\begin{tabular}{|l|l|l|l|l|l|}
\hline & $\begin{array}{c}\text { Halifax Chronicle- } \\
\text { Herald }\end{array}$ & $\begin{array}{c}\text { Toronto } \\
\text { Star }\end{array}$ & $\begin{array}{c}\text { Vancouver } \\
\text { Sun }\end{array}$ & $\begin{array}{c}\text { Maclean's } \\
\text { Magazine }\end{array}$ & TOTAL \\
\hline Total \# Articles & 81 & 67 & 27 & 2 & 177 \\
\hline & & & & & \\
\hline Name Dropping & 65 & 61 & 25 & 2 & 153 \\
\hline Personal Profiles & 0 & 2 & 1 & 0 & 3 \\
\hline
\end{tabular}

As the above chart illustrates, Cathy Jones was only profiled 3 out of the 177 sampled articles (1.7 percent), whereas Jones was a mere reference in 86.4 percent of the sampled articles. As discussed in Chapter Two, the 'illusion of intimacy' helps to create the connection between the audience and the celebrity which is crucial to the success of a star system. The print media sampled gave potential fans only a small, almost insignificant, amount of time to develop a relationship with Jones outside of her television persona.

\footnotetext{
${ }^{2}$ In the study the category celebrity profiles included interviews, biographies and career profiles.
} 
Industry versus General Interest

In presenting the celebrity as a 'real' person, the topic of the article on the celebrity is just as important as the media coverage itself. Among the articles sampled (1966), the number that focused on industry-related topics was overwhelming in comparison to other topics. Industry related topics accounted for 54.2 percent of the sampled articles, whereas general interest articles accounted for only 10.6 percent.

Industry related topics can suffocate the celebrity by not allowing the celebrity to be seen as someone other than their characters on television or in film. However, stories that focus on the human aspect of the celebrity can make that crucial connection between the audience and the celebrity. Looking specifically at Mary Walsh demonstrates this point further:

Table 4.5

\begin{tabular}{|l|l|l|l|l|l|}
\hline & $\begin{array}{c}\text { Halifax Chronicle- } \\
\text { Herald }\end{array}$ & $\begin{array}{c}\text { Toronto } \\
\text { Star }\end{array}$ & $\begin{array}{c}\text { Vancouver } \\
\text { Sun }\end{array}$ & $\begin{array}{l}\text { Maclean's } \\
\text { Magazine }\end{array}$ & TOTAL \\
\hline Total \# Articles & 99 & 152 & 83 & 6 & 340 \\
\hline & & & & & \\
\hline Industry & 49 & 69 & 45 & 2 & 165 \\
\hline General Interest & 12 & 21 & 10 & 0 & 43 \\
\hline
\end{tabular}

As the above indicates, 48.5 percent of the sampled articles referred to Mary Walsh within the industry of television and film and only 12.6 percent of the articles discussed Walsh outside of the industry. In this case it would be difficult for any audience to begin to see Walsh as a 'real person'. The articles overwhelmingly connect Walsh to industry business and neglect the whole person. Moreover, as the table on page 71 illustrates, this is the case for all the celebrities. Rarely are they mentioned beyond the parameters of the 
television and film industry. Canadian print media inadequately produce the 'illusion of intimacy' necessary for celebrity building.

\section{News-worthiness}

Similar to the 'illusion of intimacy,' newsworthiness addresses how the celebrity is seen. Ponce de Leon (2002) suggests that "to be lifted to the status of a celebrity, one must be newsworthy or interesting in the eyes of the news media, a person whom journalists think their readers or viewers want to know about" (6). Reporting on celebrities outside of their industry helps to maintain the idea that the celebrity is important.

The ability to present the celebrity in this way is another crucial task of the print media. The categories which help to determine the print media's current ability to do so include: politics, events, celebrity profiles and awards. The following table summarizes the findings of those categories:

Table 4.6

\begin{tabular}{|l|l|l|l|l|l|}
\hline Total 7 Subjects & $\begin{array}{c}\text { Halifax Chronicle- } \\
\text { Herald }\end{array}$ & $\begin{array}{c}\text { Toronto } \\
\text { Star }\end{array}$ & $\begin{array}{c}\text { Vancouver } \\
\text { Sun }\end{array}$ & $\begin{array}{c}\text { Maclean's } \\
\text { Magazine }\end{array}$ & TOTAL \\
\hline Total \# Articles & 469 & 1014 & 454 & 29 & 1966 \\
\hline & & & & & \\
\hline Awards & 116 & 141 & 83 & 0 & 340 \\
\hline Events & 34 & 84 & 25 & 0 & 143 \\
\hline Politics & 28 & 72 & 24 & 0 & 124 \\
\hline
\end{tabular}

As the above chart indicates, these three topics accounted for 30.9 percent of the sampled articles. All three topics are considered newsworthy by both journalists and the audience. This is a fairly encouraging statistic. However, the topic of 'newsworthy' is perhaps the 
most complicated component of visibility. It could be argued that the very fact that a celebrity's name is in the news means they are in some way newsworthy. However, the way in which the celebrity is covered in the news also determines their newsworthiness. For instance, reporting on a celebrity's illness or whereabouts suggests that this person is important, whereas an article highlighting the nightly television line-up that includes reference to a celebrity is less important.

Awards and Events

News articles on awards and events are what Boorstin (1972) refers to as 'pseudoevents'. The publicity these awards shows and events create, increase the importance and newsworthiness of celebrities. Take for instance, the results for Rick Mercer in these categories:

Table 4.7

\begin{tabular}{|l|l|l|l|l|l|}
\hline & $\begin{array}{c}\text { Halifax Chronicle- } \\
\text { Herald }\end{array}$ & $\begin{array}{c}\text { Toronto } \\
\text { Star }\end{array}$ & $\begin{array}{c}\text { Vancouver } \\
\text { Sun }\end{array}$ & $\begin{array}{c}\text { Maclean's } \\
\text { Magazine }\end{array}$ & TOTAL \\
\hline Total \# Articles & 131 & 189 & 84 & 3 & 407 \\
\hline & & & & & \\
\hline Awards & 51 & 30 & 16 & 0 & 97 \\
\hline Events & 5 & 7 & 0 & 0 & 12 \\
\hline Politics & 9 & 23 & 11 & 0 & 43 \\
\hline
\end{tabular}

In total Rick Mercer was associated with awards or events in 26.8 percent of the sampled articles. This suggests that Rick Mercer is a respected and important figure, one who is constantly winning awards and attending various functions. However, in reviewing these articles, his importance is less clear cut. For instance, in the events articles, the focus was 
not primarily on Mercer. They read more like 'events listings', naming off various happenings around town.

This was also the case for the articles on awards. The central focus of the awards articles were not on Mercer, but rather on the awards and only included his name among the hundreds of other names up for nomination. This type of reference is problematic because it reduces the accessibility to the celebrity and is not much better for celebrity building then name-dropping.

\section{Politics}

It is generally accepted that politics are newsworthy. Including a celebrity in an article on a political issue suggests that the celebrity has a certain amount of importance or credibility to weigh in on the issue. It suggests that the opinion offered by the celebrity on the issue is significant and that we should be aware of their thoughts. By including celebrities in these types of articles the journalist is according the celebrity a certain amount of influence.

Generally speaking, English-Canadian print media do a fairly good job at fulfilling the newsworthiness component of visibility. There were numerous occasions where celebrities were included in discussions of politics. However, the way these articles were prepared could be improved. Articles on awards were too often little more than listings which did not highlight the achievements of any specified celebrity. This could be easily improved by providing mini-profiles on the celebrities who are nominated for a Gemini or Genie Awards. 


\section{Summary of Conclusions}

As the above analysis indicates there are some obvious shortcomings in the English-Canadian print media's contribution to celebrity building. What this study suggests is that the total number of articles that directly perform celebrity making functions for English-Canadian celebrities is too low, and too skewed towards the potential celebrity's home region, to effectively support an English Canadian star system. Furthermore, the type of coverage available to the average reader is not the most conducive to cultivating celebrity. The overwhelming occurrence of name-dropping is good, in itself, and is something that we should encourage journalists to continue. Yet it does nothing to foster celebrity. The lack of prominence given celebrities in headlines, leadlines and illustrations, along with the small number of celebrity profiles, is not enough to create the star system discussed by policy makers.

The situation is still worse if we consider the amount of coverage given to actors in television drama. An interesting discovery from this research is the exposure of comedic actors versus dramatic actors. Celebrities with a higher level of exposure were mainly comedic. As the table "Total Number of Articles by Celebrity" (p.67) illustrates of the top three, two are comedic (Mercer and Walsh). This is further demonstrated in the table "Breakdown of Headlines by Celebrity" (p.68), which shows Mercer and Walsh receiving the most headlines. This is also the case for illustrations (see "Breakdown of Illustrations by Celebrity" p.69). It is also interesting to note that both Mercer and Walsh are best known for their political satire.

This is not to say that creating an English-Canadian star system is impossible. Print media can, with pro-active strategies, aid in the development of an English- 
Canadian star system. The concluding section that follows discusses some of the steps by which print media could begin to provide the level of visibility required to sustain a star system. 


\section{CONCLUSIONS}

\section{AND \\ RECOMMENDATIONS}

This study was propelled by discussions initiated by the CRTC stating that an English-Canadian star system was needed to stop the drastic decline in Canadian drama. As chapter one discusses, the CRTC came to this conclusion by referring to Quebec, which has a star system, and whose television dramatic programming has been able to maintain itself, despite the increase in reality programming. Yet, this discussion failed to make any correlation between the French-Canadian star system and the success of French-Canadian drama. As was discussed earlier, Australia is a shining example of how celebrity can be produced with an appropriate strategy. However, the Australian example suggests that celebrity building requires more than the efforts of one medium alone (as their study included print and television). Since celebrity breeds loyalty within audiences, it seems likely that an English-Canadian star system could help alleviate the crisis in Canadian drama.

The intention of this study is not to suggest Canadian print media replace news exclusively with celebrity journalism. Rather, it is a response to ongoing discussions in Canadian broadcasting policy. This study was conducted to help generate knowledge to inform these discussions. Too often we make decisions in an information vacuum. This is not the fault of any one person or institution; it is a systemic problem that afflicts the policy sector, where unanticipated problems require timely solutions. It is also a particularly Canadian problem: too often our own experience is ignored and theories developed elsewhere are unsuccessfully applied. 
Scholars are continuing to further our knowledge base by developing theories and knowledge grounded in the Canadian experience. Yet, there are many areas that have yet to be explored. Canadian media studies are one of these under-developed areas. The literature on celebrity used in this study shows we are still reliant on American studies and theories when trying to understand our own culture. This study of print media celebrity coverage in English-Canada, though limited in scope, at least relates directly to Canadian circumstances.

However, the research findings from this study suggest English-Canadian print media are not supporting celebrities to the degree necessary to make them stars. This raises the question of how print media might be better used to cultivate celebrity.

\section{Visibly Problematic: Canadian Celebrities in English-Canadian Print Media}

The celebrities in this study all have national exposure in their primary medium, television. The focus of this study was to examine the contribution of Canadian print media as a tool of the national cross-media promotion necessary to sustain a star system. Unfortunately, the conclusions of this study suggest that print media are not (in their current form) functioning as effective agents of national cross-media promotion.

As it was shown in the previous chapter, there is an obvious regional bias in the print media coverage of English-Canadian celebrities. Also, while high occurrences of name dropping help promote name recognition for the celebrities, they do not contain the type of information that creates the desired 'illusion of intimacy.' Furthermore, the amount of coverage (other than the name dropping) of English-Canadian celebrities is not adequate for the cultivation of a star system. Finally, questions are raised with specific 
implications to English-Canadian drama, since the dramatic actors received far less exposure than did the comedic actors.

For Canadian print media to function as a tool for celebrity building, they would need to transcend regional bias and print more celebrity profiles. An effort to remove the celebrity from the industry and present the whole person would also be beneficial.

These conclusions reveal print media characteristics which a celebrity building policy could address. A note of caution is, however, required. This study was limited in scope. It examined the availability and type of English-Canadian celebrity content in four print media sources. A much broader study of Canadian print media would be required to confirm and elaborate this study's findings as a reliable basis for policy formulation. For instance, the woman's magazine is considered a critical tool in celebrity visibility. A study that traces Canadian celebrity in these magazines could further elaborate on the Canadian celebrity environment.

Moreover, print media are only one factor that a successful star system relies upon. Print media, specifically newspapers, are a narrow part of the larger media landscape. Further research is needed, for example, on the extent of Canadian celebrity journalism on Canadian television. At present, there are two Canadian entertainment news-magazine television programs: CTV's "E-Talk Daily" and Global's "Inside Entertainment". There is also a Canadian specialty channel, StarTV, which dedicates itself to celebrity journalism. A content analysis of these programs is necessary to develop our knowledge of celebrity. An examination of these programs we would help policy makers formulate CRTC's decisions on licensing and regulation. 
Finally, research must be conducted on audience reception of Canadian celebrities. The knowledge available on the relationship between celebrities and audiences is based on American studies. To effectively address Canadian issues, policy must be grounded in research based on the Canadian experience.

The CRTC has good reason to be concerned with the development of an EnglishCanadian star system. The viability of the Canadian broadcasting system is of great importance to the CRTC. When a successful star system is in place, indigenous television industries seem to do well. Yet cross media initiatives required to develop an English-Canadian star system are not a matter of broadcasting policy alone. As the research has shown, celebrity is not built through one medium. However, the CRTC's overseer, Canadian Heritage, does have policy and input into multiple media sectors. Moreover, post-convergence corporate media players such as CanWest Global and BCE might well see cross media promotion to be in their own commercial interests.

In order to foster an English-Canadian star system, discussions must begin across media sectors. The possibility of developing an English-Canadian star system will depend on cooperation of various media - television, film, print - as well as publicists, managers and other private sector players. A logical next policy step should be to initiate discussions to create awareness across all of the above mentioned sectors. The Canadian Government should initiate and facilitate these discussions.

The government should by all means continue Canadian content regulations and funding mechanisms that are currently in place. The future of Canadian drama, however, depends on moving beyond these traditional approaches. The focus on audience and the need for an English Canadian star system represents the most promising new policy 
direction in the field for decades. Research that expands on the insights provided by this study, targeted policy solutions and political will are all required if this opportunity is to be exploited. 


\section{APPENDIX 1}

\section{CANADA - TOP TEN PROGRAMMES 1998}

\begin{tabular}{|c|c|c|c|}
\hline Academy Awards & Event & USA \\
\hline 1 & La Petite Vie & Sitcom & Canada \\
\hline 2 & ER & Series & USA \\
\hline 3 & Grey Cup Game '98 & Sports & Canada \\
\hline 4 & Bye Bye '98 & Event & Canada \\
\hline 5 & Emmy Awards & Event & USA \\
\hline 6 & Ally McBeal & Series & USA \\
\hline 7 & Merlin & TV Movie & USA \\
\hline 8 & Celine Dion & Concert & Canada \\
\hline 9 & Rear Window & TV Movie & USA \\
\hline 10 & & &
\end{tabular}

Source: Mediametrie in Nordicity Group Limited (2003). Viewership to Domestic Programming and Regulatory / Incentive Frameworks in OECD Countries and Canada. 


\section{APPENDIX 2}

CANADA - TOP TEN PROGRAMMES 2001

\begin{tabular}{|c|c|c|c|}
\hline & & & \\
\hline 1 & Academy Awards & Event & USA \\
\hline 2 & Academy Pre-Show & Event & USA \\
\hline 3 & Grey Cup Game 2001 & Sports & Canada \\
\hline 4 & Golden Globe Awards & Event & USA \\
\hline 5 & People's Choice Awards & Event & USA \\
\hline 6 & American Music Awards & Event & USA \\
\hline 7 & Survivor & Entertainment & USA \\
\hline 8 & Who Wants to be a Millionaire? & Game Show & USA \\
\hline 9 & Talking to Americans & Humour & Canada \\
\hline 10 & Barbara Walters & Talk Show & USA \\
\hline
\end{tabular}

Source: Mediametrie in Nordicity Group Limited (2003). Viewership to Domestic Programming and Regulatory / Incentive Frameworks in OECD Countries and Canada. 


\section{$\underline{\text { APPENDIX } 3}$}

\section{SUMMARY DOMESTIC PROGRAMMES AS A PERCENTAGE OF TOP TEN PROGRAMMES VIEWED IN 1998 AND 2001}

\begin{tabular}{|c|c|c|}
\hline Australia (Sydney) & $80 \%$ & $50 \%$ \\
\hline Australia (Melbourne) & $80 \%$ & $50 \%$ \\
\hline Belgium (North) & $100 \%$ & $100 \%$ \\
\hline Belgium (South) & $44 \%$ & $60 \%$ \\
\hline Brazil (Rio de Janeiro) & $90 \%$ & $100 \%$ \\
\hline Brazil (Sao Paulo) & $90 \%$ & $90 \%$ \\
\hline Finland & $100 \%$ & $90 \%$ \\
\hline France & $100 \%$ & $80 \%$ \\
\hline Germany & $90 \%$ & $90 \%$ \\
\hline Hungary & $70 \%$ & $60 \%$ \\
\hline Ireland & $80 \%$ & $50 \%$ \\
\hline Italy & $90 \%$ & $100 \%$ \\
\hline Mexico & $90 \%$ & $100 \%$ \\
\hline Netherlands & $100 \%$ & $90 \%$ \\
\hline New Zealand & $78 \%$ & $80 \%$ \\
\hline Norway & $90 \%$ & $100 \%$ \\
\hline Portugal & $100 \%$ & $70 \%$ \\
\hline Spain & $60 \%$ & $50 \%$ \\
\hline Sweden & $80 \%$ & $80 \%$ \\
\hline United Kingdom & $100 \%$ & $100 \%$ \\
\hline United States & $100 \%$ & $100 \%$ \\
\hline
\end{tabular}

Source: Eurodata in Nordicity Group Limited (2003). Viewership to Domestic Programming and Regulatory / Incentive Frameworks in OECD Countries and Canada. 


\section{APPENDIX 4}

\section{SUMMARY OF DRAMA AND COMEDY PROGRAM HOURS BROADCAST DURING PEAK VIEWING HOURS (7:00 PM - 11:00 PM)}

\begin{tabular}{|c|c|c|c|c|c|c|c|c|}
\hline \multicolumn{9}{|c|}{ ENGLISH } \\
\hline $\begin{array}{l}\text { CBLT-TV } \\
\text { Toronto, } \\
\text { CBC }\end{array}$ & $293: 47$ & $359: 37$ & $282: 30$ & $248: 40$ & $5: 38$ & $6: 53$ & $5: 25$ & $4: 46$ \\
\hline $\begin{array}{c}\text { CFTO-TV } \\
\text { Toronto, } \\
\text { CTV }\end{array}$ & 291:51 & $263: 34$ & $270: 58$ & $247: 31$ & $5: 35$ & $5: 03$ & $5: 11$ & $4: 44$ \\
\hline $\begin{array}{c}\text { CIII-TV } \\
\text { Toronto, } \\
\text { Global }\end{array}$ & $286: 52$ & $323: 01$ & $338: 03$ & $307: 52$ & $5: 30$ & $6: 11$ & $6: 29$ & $5: 54$ \\
\hline & & & FRF & $\mathrm{CH}$ & & & & \\
\hline $\begin{array}{c}\text { CBFT } \\
\text { Montreal, } \\
\text { SRC }\end{array}$ & $331: 29$ & $314: 22$ & $349: 44$ & $347: 30$ & $6: 21$ & 6:01 & $6: 42$ & $6: 39$ \\
\hline $\begin{array}{c}\text { CFTM-TV } \\
\text { Montreal, } \\
\text { TVA }\end{array}$ & $278: 50$ & $237: 30$ & $248: 21$ & 211:23 & $5: 20$ & $4: 33$ & $4: 45$ & 4:03 \\
\hline
\end{tabular}

Source: Canadian Radio-Television and Telecommunications Commission. (2003). Public Notice 2003-54: Support for Canadian Television Drama - Call for Comments. Ottawa, Canada. 


\section{APPENDIX 5}

\section{FILMOGRAPHIES}

\section{$\underline{\text { Rick Mercer }}$}

Actor

1. "Monday Report" (2003) TV Series...Himself

2. Christmas in Kabul (2003) (TV Special) .... Himself/Host

3. Joke's on Us: 50 Years of CBC Satire, The (2002) (TV Special) .... Himself

4. "Tuning In: Fifty Years On the CBC" (2002) TV Mini-Series ... Host

5. Talking to Americans (2001) (TV Special) .... Himself

6. "Made In Canada" (1998) TV Series .... Richard Strong

7. "It Seems Like Yesterday" (1996) TV Series...Himself/Host

8. "This Hour Has 22 Minutes" (1994) TV Series .... J.B. Dixon/other various

9. Secret Nation (1992) .... Chris Vokey

10. Understanding Bliss (1990) .... Richard (Turkish Knight)

11. Vacant Lot, The (1989)

\section{Writer}

1. "Monday Report" (2003) TV Series

2. Christmas in Kabul (2003) (TV Special)

3. Talking to Americans (2001) (TV Special)

4. This Hour Has 22 Minutes: New Year's Eve Special (1998) (TV Special)

5. "Made In Canada" (1998) TV Series

6. "This Hour Has 22 Minutes" (1994) TV Series

\section{Producer}

1. "Monday Report" (2004) TV Series

2. Christmas in Kabul (2003) (TV)

3. Talking to Americans (2001) (TV)

\section{Notable TV Guest Appearances}

1. "Life and Times" (1996) playing "Himself" in episode: "Mary Walsh: Princess Warrior" (episode \# 4.1) 5 October 1999

Source: Internet Movie Database, Accessed: 2004-07-16, http://www.imdb.com/name/nm0580300/ 


\section{APPENDIX 6}

\section{$\underline{\text { Sarah Pollev }}$}

\section{Actress}

1. Hawk Is Dying, The (2005) (announced)

2. Don't Come Knockin' (2004) (pre-production)... Sky

3. 3 Needles (2005) (filming)...Donna Cherry

4. Sugar (2004) .... Pregnant Girl

5. Dawn of the Dead (2004) .... Ana

6. I Inside, The (2003) .... Claire

7. Luck (2003) .... Margaret

8. Dermott's Quest (2003) .... Gwen

9. My Life Without Me (2003) .... Ann

10. Event, The (2003) .... Dana

11. No Such Thing (2001) .... Beatrice

12. This Might Be Good (2000)

13. Claim, The (2000) .... Hope Burn

14. Law of Enclosures, The (2000) .... Beatrice

15. Love Come Down (2000) .... Sister Sarah

16. Weight of Water, The (2000) .... Maren Hontvedt

17. Life Before This, The (1999) .... Connie

18. Go (1999) .... Ronna Martin

19. eXistenZ (1999) .... Merle

20. Guinevere (1999) .... Harper Sloane

21. Last Night (1998/I) .... Jennifer 'Jenny' Wheeler

22. White Lies (1998/I) (TV) .... Catherine Chapman

23. Jerry and Tom (1998) .... Deb

24. "Straight Up" (1997) TV Series...Lily

25. Planet of Junior Brown, The (1997) .... Butter

26. Hanging Garden, The (1997) .... Teen Rosemary

27. Sweet Hereafter, The (1997) .... Nicole

28. Children First! (1996)

29. Joe's So Mean to Josephine (1996) .... Josephine

30. Exotica (1994) .... Tracey Brown

31. Johann's Gift to Christmas (1991) (TV) .... Angel

32. Lantern Hill (1990) (TV) .... Jody Turner

33. Babar: The Movie (1989) (voice)...Young Celeste

34. "Road to Avonlea" (1989) TV Series...Sara Stanley

35. "Ramona" (1988) TV Series...Ramona Quimby

36. Adventures of Baron Munchausen, The (1988) .... Sally Salt

37. Blue Monkey (1987) .... Ellen

38. Heaven on Earth (1987) (TV)

39. Prettykill (1987) .... Karla

40. Big Town, The (1987) .... Christy Donaldson 
41. Hands of a Stranger (1987) (TV)

42. One Magic Christmas (1985) .... Molly Monaghan

\section{Director}

1. "Shields Stories, The" (2004) TV Series

2. All I Want for Christmas (2002)

3. I Shout Love (2001)

4. Best Day of My Life, The (1999)

5. Don't Think Twice (1999)

\section{Writer}

1. "Shields Stories, The" (2004) TV Series

2. I Shout Love (2001)

3. Don't Think Twice (1999)

\section{Art Department - Crew}

1. Rave (2000) (on-set dresser)

2. Sweet Hereafter, The (1997) (lyricist) (musician: vocals)

\section{Producer}

1. Don't Think Twice (1999) (co-producer)

\section{Notable TV Guest Appearances}

1. "Late Late Show with Craig Kilborn, The" (1999) playing "Herself" 15 March 2004

2. "Life and Times" (1996) playing "Narrator" in episode: "My Beat: The Life and Times of Bruce Cockburn" (episode \# 6.8) 27 November 2001

3. "Made In Canada" (1998) playing "Rhonda" in episode: "It's a Science" (episode \# 2.6) 8 November 1999

4. "Hidden Room, The" (1991) in episode: "Refuge" (episode \# 2.17) 2 October 1993

5. "Friday the 13th" (1987) playing "Mary" in episode: "The Inheritance" (episode \# 1.1) 28 September 1987

Source: Internet Movie Database. Accessed 2004-07-16:

http://www.imdb.com/name/nm0001631/ 


\section{APPENDIX 7}

\section{Paul Gross}

\section{Actor}

1. H20: The Last Prime Minister (2004) (TV) in-production...Tom McLaughlin

2. Wilby Wonderful (2004) .... Buddy French

3. "Slings and Arrows" (2003) TV Mini-Series...Geoffrey Tennant

4. "Eleventh Hour, The" (2002) playing "Tony Joel" in episode: "A Modern Mata Hari" (episode \# 1.6) 7 January 2003

5. Men with Brooms (2002) .... Chris Cutter

6. "Steelstring" (2001) TV Series...Dan Patrick

7. The Portrait of Dorian Gray (2000) Stratford, Theatre...Dorian Gray

8. Hamlet (2000) Stratford, Theatre... Hamlet

9. The Ruling Class (2000) Stratford, Theatre...Jack, $14^{\text {th }}$ Earl of Gurney

10. The Collected Works of Micheal Ondaatje (1999)...Reader

11. Murder Most Likely (1999) (TV) .... Patrick Kelly

12. "Witness to Yesterday (1998) TV Special...Alexander the Great

13. Battle of Vimy Ridge - Part 4: The Battle Joined and Won, The (1997) TV MiniSeries...Narrator

14. Battle of Vimy Ridge - Part 3: The Battle Looms, The (1997) TV MiniSeries...Narrator

15. Battle of Vimy Ridge - Part 2: Keys to Victory, The (1997) TV MiniSeries...Narrator

16. Battle of Vimy Ridge - Part 1: Setting the Stage, The (1997) TV MiniSeries...Narrator

17. "Due South" (1997) TV Series...Constable Benton Fraser

18. 20,000 Leagues Under the Sea (1997/I) (TV) .... Ned Land

19. Paint Cans (1994)...Morton Ridgewell

20. "Due South" (1994) TV Series...Constable Benton Fraser

21. Whale Music (1994) .... Daniel Howl

22. XXX's \& OOO's (1994) (TV) .... Bucky Dean

23. Due South (1994) TV Series .... Constable Benton Fraser

24. "Royal Canadian Air Farce" (1993) playing "Himself" 31 December 1997

25. "Tales of the City" (1993) TV Mini-Series...Brian Hawkins

26. Aspen Extreme (1993) .... T.J. Burke

27. Buried on Sunday (1992) .... Augustus Knickel

28. "Red Green Show, The" (1991) TV Series...Kevin Black

29. Married to It (1991) .... Jeremy Brimfield

30. "Ray Bradbury Theatre, The" (1985) in episode: "Mars Is Heaven" (episode \# 4.1) 20 July 1990

31. Getting Married in Buffalo Jump (1990) (TV) .... Alex Bresnyachuk

32. Cold Comfort (1989) .... Stephen Miller

33. Divided Loyalties (1989) .... Walter Butler

34. Cat on a Hot Tin Roof (1989) Manitoba Theatre Centre...Brick 
35. "Chasing Rainbows" (1988) TV Mini-Series...Jake Kincaid

36. Observe the Sons of Ulster Marching towards the Somme (1988) CentreStage Company, Theatre...Young Kenny Pypyer

37. "Street Legal" (1987) playing "Steven Hines" in episode: "Film Noir" (episode \# 4.7) 1989

38. "Street Legal" (1987) playing "Steven Hines" in episode: "Soul Custody" (episode \# 4.1) 1989

39. Turning to Stone (1985)

40. Romeo \& Juliet (1985) Toronto Free Theatre... Romeo

41. Successful Strategies (1985) Centaur Theatre... Dorante

42. In the Jungle of Cities (1983) Toronto Free Theatre...George Garga

43. Walsh (1983) National Arts Centre...Constable Clarence Underhill

44. The Kite (1982) Festival Lennoxville... Motherwell

45. Take Me Where the Water's Warm (1982) Festival Lennoxville...Donald

Lampert

46. The Deer and the Antelope Play (1982) Theatre Network...Woody, CC, Mary, Jimmy

47. Farther West (1982) Theatre Calgary...Raglan

48. Unseen Hand (1982) Theatre Calgary

49. Mrs. Warren's Profession (1981) Theatre Calgary...Frank Gardner

50. The Winter's Tale (1981) Northern Light Theatre...Florizel

51. St. Joan (1981) Northern Light Theatre...Attendant, Dunois, D'Estivet

52. As You Like It (1980) Northern Lights Theatre...Silvius

53. A Midsummer Nights Dream (1980) Northern Lights Theatre...Lysander

\section{Writer}

1. H20: The Last Prime Minister (2004) (TV) in production (co-writer)

2. Men with Brooms (2002) (story)

3. "Due South" (1994) TV Series (writer)

4. Gross Misconduct (1993/II) (TV)

5. In This Corner (1985) (TV)

\section{Producer}

1. H20: The Last Prime Minister (2004) (TV) in production (executive/producer)

2. Murder Most Likely (1999) (TV) (executive producer)

3. "Due South" (1997) TV Series (executive producer)

4. "Due South" (1994) TV Series (executive producer)

\section{Director}

1. Men with Brooms (2002)

\section{Composer}


1. Men with Brooms (2002)

Source: Internet Movie Database. Accessed 2004-07-16:

http://www.imdb.com/name/nm0343472/ 


\section{APPENDIX 8}

\section{Cathy Jones}

Actor

1. Cathy Jones Gets a Special (2002) (TV Special) .... Various roles

2. Joke's on Us: 50 Years of CBC Satire, The (2002) (TV Special) .... Herself

3. Frank Truth, The (2001) .... Herself (comedian)

4. Congratulations (2000)

5. Voice Set Free, The (2000) (TV) .... Narrator

6. "This Hour Has 22 Minutes" (1994) TV Series... Various Roles

7. Secret Nation (1992) .... Frieda Vokey

8. Adventure of Faustus Bidgood, The (1986) .... Margaret May Stackdeck

9. "Codco" (1986) TV Series .... Regular

\section{Writer}

1. Cathy Jones Gets a Special (2002) (TV Special)

2. This Hour Has 22 Minutes: New Year's Eve Special (1998) (TV Special)

3. "This Hour Has 22 Minutes" (1994) TV Series

\section{Producer}

1. Cathy Jones Gets a Special (2002) (TV) (producer)

\section{Notable TV Guest Appearances}

1. "Life and Times" (1996) playing "Herself" in episode: "Mary Walsh: Princess Warrior" (episode \# 4.1) 5 October 1999

Source: Internet Movie Database. Accessed 2004-07-16:

http://www.imdb.com/name/nm0427713/ 


\section{APPENDIX 9}

\section{Mary Walsh}

Actor

1. Piggy Bank Blues (2004) (post-production)...Rose

2. Strategic Humor Initiative, The (2003) (TV) .... Herself

3. Mambo italiano (2003) .... Lina Paventi

4. Joke's on Us: 50 Years of CBC Satire, The (2002) (TV) .... Herself

5. Behind the Red Door (2002) .... Anna

6. Bleacher Bums (2002) (TV) .... Rose

7. "Random Passage" (2002) (mini) TV Series...Mrs. Armstrong

8. "Mary Walsh: Open Book" (2002) TV Series...Herself/Host

9. Frank Truth, The (2001) .... Herself (comedian)

10. Violet $(2000 / \mathrm{II})$.... Violet

11. Divine Ryans, The (1999) .... Aunt Phil Ryan

12. New Waterford Girl (1999) .... Cookie Pottie

13. "Dooley Gardens" (1999) TV Series .... Marilyn Benoit

14. Extraordinary Visitor (1998) .... Marietta

15. Rain, Drizzle, and Fog (1998)

16. Major Crime (1997) (TV) .... Patty Reckles

17. "New Adventures of Robin Hood, The" (1997) playing "Police Guard \#1" in episode: "Outlaw Express" (episode \# 2.9) 4 October 1997

18. "Lexx" (1997) TV Series...Heedia in episode: "Twilight" (episode \# 2.13) 5 March 1999

19. "This Hour Has 22 Minutes" (1994) TV Series...Various Roles

20. Boys of St. Vincent: 15 Years Later, The (1993) .... Lenora

21. Secret Nation (1992) .... Oona Vokey

22. Buried on Sunday (1992) .... 2nd biker

23. Adventure of Faustus Bidgood, The (1986) .... Heady Nolan

24. "Codco" (1986) TV Series... Regular

25. "Up at Ours" (1980) TV Mini-Series...Verna Ball

\section{Writer}

1. Bailey's Billion\$ (2004) post-production

2. "Mary Walsh: Open Book" (2002) TV Series

3. This Hour Has 22 Minutes: New Year's Eve Special (1998) TV Special

4. "This Hour Has 22 Minutes" (1994) TV Series (creator)

\section{Producer}

1. "Mary Walsh: Open Book" (2002) TV Series

2. "Codco" (1986) TV Series 


\section{Notable TV Guest Appearances}

1. "Open Mike with Mike Bullard" (1997) playing "Herself" 31 May 2002

2. "Life and Times" (1996) playing "Herself" in episode: "Mary Walsh: Princess Warrior" (episode \# 4.1) 5 October 1999

Source: Internet Movie Database. Accessed 2004-07-16:

http://www.imdb.com/name/nm0909763/ 


\section{APPENDIX 10}

\section{$\underline{\text { Sonja Smits }}$}

Actor

1. How to Deal (2003)...Carol Warsher

2. "Atwood Stories, The" (2003) TV Series...Mrs. Anderson (Man from Mars)

3. Owning Mahowny (2003) .... Dana Selkirk

4. Minor Adjustments (2002) .... Clare's Agent

5. "Eleventh Hour, The" (2002) TV Series....Megan Redner

6. Moms On Strike (2002) (TV) .... First Lady

7. "Odyessy 5" (2002) TV Series...Cynthia Hodge

8. Life with Judy Garland: Me and My Shadows (2001) (TV) .... Kay Thompson

9. Hidden Heroes (1999) .... Narrator

10. Nothing Sacred (1998) (TV)

11. Dead Husbands (1998) (TV) .... Sheila Feinstein

12. "Traders" (1996) TV Series .... Sally Ross

13. "Outer Limits, The" (1995) TV Series...Anne Crain in episode: "White Light Fever" (episode \# 1.5) 21 April 1995

14. TekWar: TekLords (1994) (TV) .... Kate Cardigan

15. TekWar (1994) (TV Movie) .... Kate Cardigan

16. Spenser: Pale Kings and Princes (1994) (TV) .... Carolyn Rogers

17. Diviners, The (1993) (TV) .... Morag

18. "Counterstrike" (1990) TV Series...Julia Devane in episode: "Betrayed" (episode \# 3.13) 9 January 1993

19. "Street Legal" (1987) TV Series...Carrington 'Carrie' Barr (1986-1992)

20. "Airwolf" (1987) in episode: "Stavograd: Part 2" (episode \# 1.10) 27 March 1987

21. "Airwolf" (1987) in episode: "Stavograd: Part 1" (episode \# 1.9) 20 March 1987

22. Screwball Academy (1986) (TV) .... Carla

23. "Ray Bradbury Theatre, The" (1985)...Mary in episode: "The Fruit at the Bottom of the Bowl" (episode \# 2.1) 23 January 1988

24. Command 5 (1985) (TV) .... Chris Winslow

25. That's My Baby! (1984) .... Suzanne

26. Videodrome (1983) .... Bianca O'Blivion

27. "Hitchhiker, The" (1983) TV Series... Nina Russell in episode: "Face to Face" (episode \# 1.5) 27 November 1984

28. Pit, The (1981) .... Mrs. Lynde

29. "Fall Guy, The" (1981) TV Series...Jessica Beaumont in episode: "Her Bodyguard" (episode \# 4.14) 9 January 1985

30. War Brides (1980) (TV) .... Lisa

Source: Internet Movie Database. Accessed 2004-07-16:

http://www.imdb.com/name/nm0810500/ 


\section{APPENDIX 11}

\section{Nicholas Campbell}

Actor

1. "Human Cargo" (2004) TV Mini-Series...Jery Fisher

2. 100 Days in the Jungle (2002) (TV)

3. Making of 'We All Fall Down', The (2002) (V) .... Himself

4. "Monk" (2002) TV Series...Grayson in episode: "Mr. Monk and the Other Woman" (episode \# 1.8) 23 August 2002

5. Full Disclosure (2001)... Simon

6. "Nero Wolfe Mystery, A" (2001) TV Series...Andrew Krasicki in episode: "Door to Death" (episode \# 1.8) 24 June 2001

7. "Nero Wolfe Mystery, A" (2001) TV Series...Colonel Percy Brown in episode: "Disguise for Murder" (episode \# 1.7) 16 June 2001

8. "Blue Murder" (2001) TV Series...Eugene Sandler in episode: "Steel Drums" (episode \# 1.6) 7 February 2001

9. Turning Paige (2001) .... Ross Fleming

10. Prozac Nation (2001) .... Donald

11. New Year's Day (2001)...Ollie

12. We All Fall Down (2000)...Bruce

13. Saint Jude (2000)...Jude's Father

14. New Waterford Girl (1999)...Francis Pottie

15. Happy Face Murders (1999) (TV)...Rusty Zuvic

16. "Code Name: Eternity" (1999) TV Series... Bryce in episode: "Fatal Error" (episode \# 1.15) 27 August 2000

17. Hard to Forget (1998) (TV)...Doug Hart

18. "Da Vinci's Inquest" (1998) TV Series...Dominic Da Vinci

19. Thanks of a Grateful Nation (1998) (TV)...Rep. Joseph Kennedy

20. East Side Showdown (1998) .... Narrator

21. Cool, Dry Place, A (1998)...Frankie Gooland

22. Sleep Room, The (1998)...Lucas

23. Blood on Her Hands (1998) (TV)...Doggett

24. Major Crime (1997) (TV)...Billy Quinn

25. "Spoken Art" (1997) TV Series...Simon in episode: "The Two Headed Man" 9 July 1997

26. "Spoken Art" (1997) TV Series...in episode: "The Sugar Jigsaw"

27. "Spoken Art" (1997) TV Series...in episode: "Winter Baby"

28. Boys Club, The (1997)...Kyle's Dad

29. "Hunger, The" (1997) TV Series...Robert Wallace in episode: "The Other Woman" (episode \# 1.20) 20 March 1998

30. "Prince Street" (1997) TV Series...in episode: "Father and Sons" (episode \# 1.5) 2000

31. Mother Trucker: The Diana Kilmury Story (1996) (TV)...Jack Vlahovic

32. We the Jury (1996) (TV)...Karl Weber 
33. No Greater Love (1996) (TV)...Malcolm Stone

34. "Black Harbour" (1996) TV Series...Tom Wyler in episode: "Turnaround" (episode \# 1.8) 5 February 1997

35. "F/X: The Series" (1996) TV Series...Colonel Stewart in episode: "White Light" (episode \# 1.8) 21 October 1996

36. "Psi Factor: Chronicles of the Paranormal" (1996) TV Series...Russell Beacham in episode: "The Winding Cloth" (episode \# 3.11)

37. Butterbox Babies (1995)...Clayton Oliver

38. Jungleground (1995)... Robert Neilson

39. Dancing in the Dark (1995) (TV)...Mark Forbes

40. "Outer Limits, The" (1995) TV Series...Frank Daniels in episode: "Better Luck Next Time" (episode \# 5.22) 20 August 1999

41. Guitarman (1994) (TV)...Jack Tibbins

42. Lust of His Eyes, The (1994) (TV)...James Wilson Morrice

43. "Due South" (1994) TV Series...Nigel Ellis in episode: "An Invitation to Romance" (episode \# 1.18) 6 April 1995

44. No Contest (1994)...Vic

45. Betrayal of Trust (1994) (TV)...Richard Noel

46. "Royal Canadian Air Farce" (1993) TV Series...Dominic Da Vinci 31 December 2000

47. Bordertown Café (1993)...Don

48. "Kung Fu: The Legend Continues" (1993) TV Series...Graham Corrigan in episode: "Eye Witness" (episode \# 3.13) 24 July 1995

49. Diary of Evelyn Lau, The (1993) (TV)...Man on Highway

50. Split Images (1992) (TV)...Bryan Hurd

51. Shadow of the Wolf (1992)...Scott

52. "Highlander" (1992) TV Series...Kit O'Brady in episode: "Double Eagle" (episode \# 4.5) 23 October 1995

53. In Desperate Battle: Normandy 1944 (1992) (TV)...Guy Simonds

54. Big Slice, The (1991)... Nick

55. "Beyond Reality" (1991) TV Series...Tom Becker in episode: "Range of Motion" (episode \# 1.7) 15 November 1991

56. Shadows of the Past (1991)...MacFern

57. Naked Lunch (1991)....Hank

58. In Defense of a Married Man (1990) (TV)... Ben Gardner

59. "Counterstrike" (1990) TV Series...Westic in episode: "Power Play" (episode \# 1.5) 29 July 1990

60. Rampage (1988)...Albert Morse

61. Going Home (1987)...Cpl. Brill

62. Pink Chiquitas, The (1987)... Cast Member of Zombie Beach Party III

63. Shades of Love: Champagne for Two (1987)...Vincent

64. Hoover vs. the Kennedys: The Second Civil War (1987) (TV)...Bobby Kennedy

65. "Diamonds" (1987) TV Series...Mike Devitt

66. "Street Legal" (1987) TV Series...Tom Morgan

67. Knights of the City (1986)...Joey

68. Dark Horse (1985) (TV) 
69. Children of the Night (1985) (TV)...Larry

70. "Insiders, The" (1985) TV Series....Nick Fox

71. Terminal Choice (1985)...Henderson

72. Certain Fury (1985)...Sniffer

73. "Airwolf" (1984) TV Series...Jason 'Doc' Gifford

74. "Hitchhiker, The" (1983) TV Series...The Hitchhiker (1983-1984)

75. Dead Zone, The (1983)...Frank Dodd

76. Love (1982)...Danny (segment "For Life")

77. Killing 'em Softly (1982)...Clifford

78. Trapped (1982)...Roger Michaels

79. "T.J. Hooker" (1982) TV Series... Toby Clark in episode: "Death Strip" (episode \# 3.19) 10 March 1984

80. July Group, The (1981) (TV)

81. Amateur, The (1981)...Schraeger

82. Just Jessie (1981) (TV)...Mac

83. Dirty Tricks (1981)...Bill Darcy

84. Yesterday (1981)...Tony

85. Fukkatsu no hi (1980)...Oparator (US-Base)

86. Brood, The (1979)...Chris

87. "Littlest Hobo, The" (1979) TV Series...Roger Houghton in episode: "The Hunt" (episode \# 2.9) 20 November 1980

88. Shape of Things to Come, The (1979)...Jason Caball

89. Fast Company (1979)...Billy 'The Kid' Brocker

90. Come Back, Little Sheba (1977) (TV)...Turk

91. Spy Who Loved Me, The (1977)...USS Wayne Crewman

92. Bridge Too Far, A (1977)...Capt. Glass

93. Omen, The (1976)...Marine

94. "Space: 1999" (1975) TV Series...Eddie Collins in episode: "A Matter of Balance" (episode \# 2.15) 10 December 1976

95. "Bless This House" (1971) TV Series...Roger in episode: "Some Enchanted Evening" (episode \# 6.13) 22 April 1976

\section{Director}

1. "Da Vinci's Inquest" (1998) TV Series

2. Boozecan (1994)

3. Stepping Razor: Red X (1992)

4. Murder One (1988) (third assistant director)

5. Caribe (1987) (third assistant director)

\section{Writer}

1. Stepping Razor: Red X (1992)

2. "Diamonds" (1987) TV Series (writer) 


\section{Notable TV Guest Appearances}

1. "Open Mike with Mike Bullard" (1997) playing "Himself" 9 August 2002

Source: Internet Movie Database. Accessed 2004-07-16:

http://www.imdb.com/name/nm0132757/ 


\section{BIBLIOGRAPHY}

Acland, Charles. (2001). "From Absent Audience to Expo-Mentality," A Passion for Identity. Eds. David Taras and Beverly Rasporich. Toronto: Nelson. 275-291.

Alberoni, Francesco. (1972). "The "Powerless Elite," in Sociology of Mass Communication. Ed. D. MacQuail. Harmondsworth: Penguin.

Ang, Ien. (1991). Desperately seeking the Audience. New York: Routledge.

Attallah, Paul. (1992). "Richard Collins and the Debate on Culture and Polity." Canadian Journal of Communication. 17(2).

Auletta, Ken. (1991). Three Blind Mice: How the TV Networks Lost Their Way. New York: Random House.

Audley, Paul. (1994). "Cultural Industries Policy: Objectives, Formulation, and Evaluation," Canadian Journal of Communication, 19 (no. 3-4).

Barbas, Samantha. (2001). Movie Crazy: Fans, Stars, and the Cult of Celebrity. New York: Palgrave.

Barwise, Patrick and Andrew Ehrenberg. (1988). Television and its Audience. London: Sage Publications.

Benjamin, W. (1977). Illuminations, London: Fontana.

Berlin, Barry. (1990). The American Trojan Horse: U.S. Television Confronts Canadian Economic and Cultural Nationalism. New York: Greenwood Press.

Bird, Roger, ed (1988). Documents of Canadian Broadcasting. Ottawa: Carleton University Press.

Boorstin, Daniel, J. (1961). The Image: A guide to Pseudo-Events in America. New York: Harper and Row Publications.

Braudy, Leo. (1986). The Frenzy of Renown: Fame and its History. New York: Oxford University Press.

Canada. Standing Committee on Canadian Heritage. (2003). Our Cultural Sovereignty: The Second Century of Canadian Broadcasting. Canada.

----. (1996). Making Our Voices Heard: Canadian Broadcasting and Film for the $21^{\text {st }}$ Century. Ottawa: The Committee.

---. (1991). Broadcasting Act. Ottawa: ----. 
---. (1957). The Royal Commission on Broadcasting. Ottawa: King's Printer.

-.-. (1951). The Royal Commission on National Development in the Arts, Letters and Sciences, 1949-1951. Ottawa: King's Printer.

Canadian Association of Broadcasters. (2003). A Submission to the Canadian RadioTelevision and Telecommunications Commission with Respect to Broadcasting Public Notice CRTC 2003-54: Support for Canadian Drama - Call for Comments.

---. (1998). A Submission to the Canadian Radio-Television and Telecommunications Commission with Respect to Broadcasting Public Notice CRTC 1998-44: Call for Comments - Canadian Television Policy Review: Final Comments. Prepared by the Television Board.

---. (1998). Canadian Television Policy Review: CAB Television Board Submission.

Canadian Broadcasting Corporation. (2003). Comments: Public Notice CRTC 2003-54: Support for Canadian Television Drama.

Canadian Broadcasting Corporation Research. (1991). How People Use Television: A Review of TV Viewing Habits.

Canadian Cable Television Association. (2003). Broadcasting Public Notice CRTC 2003-54, Call for Comments - Support for Canadian Television Drama.

Canadian Coalition of Audio-visual Unions. (2003). Addressing the Crisis in Canadian English-Language Drama, Submission of the Coalition of Canadian Audio-visual Unions (CCAU) to the CRTC re: Public Notice CRTC 2003-54: Support for Canadian Television Drama.

---. (2003). The Crisis in Canadian English-Language Drama.

Canadian Film and Television Production Association. (2003). Response to Broadcasting Public Notice 2003-54: CRTC Call for Comments on support for Canadian television drama.

Canadian Media Research Inc. (2003). Trends in TV 2003: Attitudes Toward and Viewing to Canadian TV Drama. Ottawa, Canada: Commissioned by the Canadian Association of Broadcasters.

Canadian Radio-Television and Telecommunications Commission. (2003). Broadcasting Policy Monitoring Report 2003. Ottawa, Canada.

---. (2003). Public Notice 2003-54: Support for Canadian Television Drama - Call for Comments. Ottawa, Canada. 
---. (1999). Building on Success: A Policy Framework For Canadian Television.

Ottawa, Canada.

----. (1998). Public Notice 1998-44: Canadian Television Policy Review - Call for

Comments. Ottawa, Canada.

----. (1979). Special Report on Broadcasting in Canada, 1968-1978. Ottawa: Canadian Radio-Television Telecommunications Commission.

Canadian Television Fund. (2003, November 17). Canadian Television Fund Overhauled: New Focus on Attracting Audiences and Simplifying Administration. http://www.canadiantelevisionfund.ca/frames 1/frame5_corp.htm [2003, December 7].

Collins, Richard. (1995). "Reflections Across the Atlantic: Contrasts and Complementarities in Broadcasting Policy in Canada and the European Community in the 1990s," Canadian Journal of Communication, 20 (no. 4).

----. (1990). Culture, Communication and National Identity: The Case of Canadian Television. Toronto: University of Toronto Press.

----. (1990). Television: Policy and Culture. London: Unwin Hyman.

Dalfen, Charles. (2002, July 15). "Wanted More TV Drama," (Interviewed by Macleans Editors). Macleans, 41-42.

Dean, Jodi. (2002). Publicity's Secret: How Technoculture Capitalizes on Democracy. Ithaca: Cornell University Press.

deCordova, Richard. (1990). Picture Personalities: The Emergence of the star system in America. Chicago: University of Illinois Press.

Department of Communications. (1988). Canadian voices, Canadian choices: A new Broadcasting Policy for Canada. Ottawa: Minister of Supply and Services Canada.

---.. (1986). Report of the Task Force on Broadcasting Policy[Caplan-Sauvageau]. Ottawa: Minister of Supply and Services.

----. (1982). Report of the Federal Cultural Policy Review Committee[ApplebaumHébert]. Ottawa: Minister of Supply and Services.

Dyer, Richard. (1998). Stars. London: British Film Institute. 
Eaman, Ross A. (1994). Channels of Influence: CBC Audience Research and the Canadian Public. Toronto: University of Toronto Press.

Ellis, David. (1991). Networking: How Are Canada's English TV Networks Performing? Toronto: Friends of Canadian Broadcasting.

Feldman, Seth. (2001). “Canadian Movies, Eh?” Lecture. Fifteenth Annual Robarts Lecture. Toronto, 5 April 2001.

Finn, A., McFadyen, S., and Hoskins, C.. (1994). "Marketing, Management, and Competitive Strategy in the Cultural Industries." Canadian Journal of Communications 19(3-4). $<$ http://www.cjc-online.ca/title.php3?page $=12 \&$ _ournal_id $=18>[2003$, September 22].

Foote, John. (2002). "Cultural Consumption and Participation." Department of Canadian Heritage: Strategic Research and Analysis.

Fournier, Guy. (2003). What about Tomorrow?: A Report on Canadian FrenchLanguage Drama. Canada: Canadian Radio-Television Telecommunications Commission and Telefilm Canada.

Fowles, Jib. (1992). Starstruck: Celebrity Performers and the American Public. Washington: Smithsonian Institution Press.

Friends of Canadian Broadcasting. (2003). Submission to the CRTC from Friends of Canadian Broadcasting: Broadcasting PN CRTC 2003-54: Support for Canadian Television Drama.

Gabler, Neal. (1994). Winchell: Gossip, Power, and the Culture of Celebrity. New York: Knopf.

Gamson, Joshua. (1994). Claims to Fame: Celebrity in Contemporary American. Los Angeles: University of California Press.

Gasher, Mike. 1998. " Invoking Public Support for Public Broadcasting: The Aird Commission Revisited," Canadian Journal of Communication, vol. 23 (no. 2).

Globerman, Steven. (1989). "What we know and don't know about the economics of culture." In Cultural economics: A Canadian perspective '88 Harry Hillman Charter and, William S. Hendon, \& Claire McCaughey (Eds.), Ottawa: Association for Cultural Economics, (3-20).

---. (1983). Cultural regulation in Canada. Montreal: Institute for Research on Public Policy. 
Grant, Peter S. (1991). The Annotated 1991 Broadcasting Act. Toronto: McCarthy Tétrault.

Hallman, E.S. and Hindley, H. (1977). Broadcasting in Canada. London: Routledge and the International Institute of Communications.

Hamilton, Peter and Roger Hargreaves. (2001). The Beautiful and the Damned: The Creation of Identity in Nineteenth Century Photography. London, England: Lund Humphries in association with the National Portrait Gallery.

Harcourt, Peter. (1978). "The Invisible Cinema", Cine Tracts. (1)4, 48-49.

Hardin, Herschel. (1985). Closed Circuits: The Sellout of Canadian Television. Toronto: Douglas \& McIntyre.

Harrington, C. Lee and Bielby, Denise D. (Eds). (2001). Popular Culture: Production and Consumption. Malden, Massachusetts: Blackwell Publications.

Hoskins, Colin., McFadyen, Stuart., and Adam Finn. (1997). Global Television and Film: An introduction to the economics of the Business. New York: Oxford University Press.

Hoskins, Colin and Stuart McFadyen. (1975). Canadian Broadcasting: The Challenge of Change. Edmonton: University of Alberta Press.

Jeffrey, Liss. (1994). "Rethinking Audiences for Cultural Industries: Implications for Canadian Research." Canadian Journal of Communications 19, no.3-4. http://www.cjc-online.ca/title.php3?page=11\&journal_id=18 [2003, September 22].

Juliani, John. (2003). "National Identity: Is it a Lost Cause?" The Newsletter of the Union of B.C. Performers (May 2003): 1-2.

Kubey, Robert and Mihaly Csikszentmihalyi. (1990). Television and the Quality of Life: How Viewing Shapes Everyday Experience. Hillsdale, NJ: Lawrence Erlbaum Associates.

Langer, John. (1998). Tabloid Television: Popular Television and 'Other News'. London: Routledge.

Lorimer, Rowland and Wilson, Donald. Eds. (1988) Communication Canada: Issues in Broadcasting and New Technologies. Toronto: Kagan and Woo.

Lumby, Catharine. (1999). Gotcha: Life in a Tabloid World. St Leonards: Allen and Unwin. 
MacDonald, J. Fred. (1990). One Nation Under Television. Toronto: Random House.

Manhant, Edelgard E. and Graeme S. Mount. (2001). "The U.S. Cultural impact upon Canada," American Review of Canadian Studies, 31 (no. 3, Autumn), 449-68.

Macerola, François. (2003). Canadian Content in the $21^{\text {st }}$ Century in film and television productions: A Matter of Cultural Identity. Hull, Quebec: Canadian Heritage.

Marshall, David P. (1997). Celebrity and Power: Fame in Contemporary Culture. Minneapolis: University of Minnesota.

---- (1992). Celebrity and Power: Celebrity Status as a Representation of Power in Contemporary Culture. Unpublished Master's Thesis, McGill University, Montreal, Quebec.

Maule, Christopher. (2003). "State of the Canada-U.S. Relationship: Culture," $\underline{\text { American }}$ Review of Canadian Studies, 33 (no. 1, Spring), 121-44.

McArthur, Benjamin. (1984). Actors and American Culture 1880-1920. Philadelphia: Temple University Press.

McChesney, Robert W. 1999. " Graham Spry and the Future of Public Broadcasting: The 1997 Spry Memorial Lecture," Canadian Journal of Communication, vol. 24 (no. 1).

McCormack, Themla H. (1959). "Canada's Royal Commission on Broadcasting," Public Opinion Quarterly, 23 (no. 1, Spring), 92-100.

McFadyen, Stuart and Adam Finn. (2000). "Cultural Industries from an Economic / Business Research Perspective," Canadian Journal of Communication, 25 (no. 1).

McFadyen, Stuart., Hoskins, Colin and David Gillen. (1980). Canadian Broadcasting: Market Structure and Economic Performance. Montreal: Institute for Research on Public Policy.

McQueen, Trina. (2003). Dramatic Choices: A Report on Canadian English-Language Drama. Canada: Canadian Radio-Television Telecommunications Commission and Telefilm Canada.

Miller, Mary Jane. (1987). Turn up the Contrast: CBC television drama since 1952. Vancouver: University of British Columbia Press.

Monaco, James. (1978). Celebrity: the media as image-makers. New York: Dell. 
Nash, Knowlton. (2001). The Swashbucklers: The Story of Canada's Battling Broadcasters. Toronto: McClelland and Stewart.

Ndalianis, Angela and Charlotte Henry. (2002). Stars in Our Eyes: The Star Phenomenon in the Contemporary Era. Connecticut: Praeger.

Nordicity Group Ltd. (2003). Evaluation of the 'Dramatic Choices' Report: Economic Considerations of Certain Audience-based Incentives.

----. (2003). Viewership to Domestic Programming and Regulatory / Incentive Frameworks in OECD Countries and Canada.

Ponce de Leon, Charles L. (2002). Self-Exposure: Human Interest Journalism and the Emergence of Celebrity in America, 1890-1940. Chapel Hill: University of North Carolina Press.

Raboy, Marc. (1991). "Canadian Broadcasting, Canadian Nationhood: Two Concepts, Two Solitudes, and Great Expectations," Electronic Journal of Communication, vol. 1 (no. 2).

----. (1990). Missed Opportunities: The Story of Canada's Broadcasting Policy. Montreal: McGill-Queen's University Press.

Rein, Irving J. (1997). High Visibility: The Making and Marketing of Professionals into Celebrities. Lincolnwood, Illinois: NTC Business Books.

Rojek, Chris. (2001). Celebrity. London: Reaktion Books

Schickel, Richard. (1986). Intimate Strangers: The Culture of Celebrity. New York: Fromm International Publishing Corporation.

Smith, Joel. (1999). "Unwarranted Hopes and Unfulfilled Expectations: Canadian Media Policy and the CBC," Canadian-American Public Policy, 39 (July), 1-58.

Symons, T.H.B. (1975). To Know Ourselves. Ottawa: Canada.

Rein, Irving J. (2003). High Visibility: The Making and Marketing of Professionals into Celebrities. Chicago, Illinois: NTC Business Books.

Thomas, Terrance. (1987). Television and Culture: The Quest for National Identity. Ottawa: Library of Parliament, Economics Division.

Turner, Graeme, Frances Bonner and P. David Marshall. (2000). Fame Games: The Production of Celebrity in Australia. Cambridge, U.K.: Cambridge University Press. 
Wall Communications. (2003). Environmental Scan of Funding for Canadian English Language Television Programming. Commissioned by the Canadian Association of Broadcasters.

Woodward, Gary C. (2003). The Idea of Identification. Albany: State University of New York Press. 